\title{
The many faces of tumor necrosis factor signaling in the intestinal epithelium
}

\author{
M. Eugenia Delgado ${ }^{1} \cdot$ Thomas Brunner $^{1}$
}

\begin{abstract}
The intestinal epithelium represents an exquisite complex combination of specialized cellular components, structural organization, as well as fine-tuned maintenance and renewal mechanisms that ensure its barrier and absorptive function. Defects in one or more of these components can lead to devastating consequences for the organisms, and when chronic, even develop into inflammatory diseases, such as Crohn's disease or ulcerative colitis. In these scenarios, the cytokine TNF (Tumor Necrosis Factor $\alpha$ ) appears to be a major inflammation-promoting and tissue damage-promoting effector molecule. Besides its role in inflammation and cell death, TNF presents a wide range of pleiotropic activities with implications in various cellular processes, including proliferation and differentiation. Moreover, more recent evidences suggest an antiinflammatory role of TNF, mostly via the induction of local glucocorticoids synthesis in the intestinal epithelium. Thus, the outcome of TNF receptor signaling largely depends on various factors, like the TNFR composition and the precise cellular context or tissue type, which will determine the cellular fate. In this review, we discuss the molecular mechanisms and their potential crosstalk that regulate the different TNF-initiated cellular outcomes in the intestine, as well as possible applications for pharmacological interventions in the treatment of inflammatory disorders of the intestinal mucosa.
\end{abstract}

\section{Highlights}

- TNF stimulation leads to survival, inflammation, apoptosis and necroptosis induction, depending on the cellular background and the disruption of specific checkpoints.

- The intestinal epithelium is exquisitely sensitive to TNF-induced cell death.

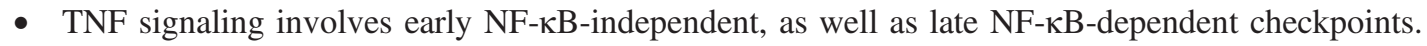

- TNF-induced cell death is often associated with intestinal immunopathologies, such as inflammatory bowel disease.

- TNF induces local intestinal glucocorticoid synthesis, which regulates immune homeostasis in the intestinal mucosa.

\section{Structure and barrier function of the intestinal epithelium}

The single-cell layer of the intestinal epithelium is considered the largest contact zone between the body and the external environment [1]. Besides its important function in the absorption of nutrients, it also plays a critical role as a physical barrier to prevent invasion by luminal pathogens. Disruption of this epithelial barrier results in a wide range of

M. Eugenia Delgado

eugenia.delgado@uni-konstanz.de

1 Chair of Biochemical Pharmacology, Department of Biology, University of Konstanz, Konstanz, Germany inflammatory pathologies with potentially devastating consequences for the organism. Importantly, an efficient and proper function of this intestinal barrier highly relies on its specialized cellular composition, structural organization, as well as fine-tuned maintenance and renewal mechanisms.

The intestinal epithelial layer is a folded surface organized in two types of evagination: one facing into the underlying connective tissue known as crypts of Lieberkühn, and the other one being a finger-like protrusion towards the lumen, called villi $[1,2]$. These special structures are found in the small intestine. Although the colon presents a comparable modular organization in crypt areas, it has a flat epithelial surface with no villi [2].

Four different specialized terminally differentiated cell types form the intestinal epithelial layer. Among them, absorptive epithelial cells, also called enterocytes, mucus- 
producing goblet cells and hormone-secreting entero-endocrine cells are localized along the crypt-villus axis, while Paneth cells, secretory cells with important anti-bacterial compounds stored in their granules, are found at the bottom of the crypts (reviewed in ref. [2]). Pluripotent stem cells and transit-amplifying, partially differentiated, cells reside also in the crypts, and are responsible for the stunning proliferative and self-renewing capacities of the intestine [1].

Intestinal epithelial cells (IECs) have a fast renewal capacity that substantially contributes to the intestinal functionality. Depending on their differentiation fate, the newly generated cells migrate towards the villus tip over a period of 3-4 days, where they are finally shed into the lumen [2, 3]. However, Paneth cells are an exception. According to different hypotheses, Paneth cells either remain at the same spot or migrate towards the bottom of the crypts. Unlike absorptive epithelial cells, Paneth cells have a live span of 18-23 days [4-7]. Epithelial cell shedding under physiological conditions is restricted to the villus tip and, more importantly, occurs without disturbing the epithelial barrier integrity (reviewed in ref. [8]). The mechanism driving this process is thought to be dependent on the physical pressure generated by the upwardsmigrating new cells pushing the older cells up and out, in order to assure their own space in the epithelial layer [9]. However, the specific signaling events regulating this process are still under debate [6, 10]. Noteworthy, this mechanism assures a delicate balance between differentiation and selfrenewal, permitting the complete renovation of the intestinal epithelium within 4-6 days, while maintaining the intestinal barrier properties $[2,6,10]$.

Different epithelial cells are connected to each other via junctional complexes, such as tight junctions (TJ) and adherence junctions. These junctions play an essential role in the cell-to-cell communications, as well as in the maintenance of the epithelial barrier integrity [6]. Finally, another cellular key component in the intestinal epithelium with an important role in the intestinal barrier function are the mucus-producing goblet cells. The secretory goblet cells produce and store mucus in vacuole-like structures that, once released, cover the entire epithelial layer. This thick mucus layer is formed mostly by large glycoproteins, called mucins, that confer the required properties to the mucus layer to form a primary physical barrier against microbial aggressions [11]. Interestingly, this physical barrier formed by the intestinal mucosa allows the efficient absorption of nutrients, while it prevents the penetration of large molecules and the adherence or penetration of luminal bacteria to, resp. through, the epithelial layer (reviewed in ref. [12]). Since, especially during inflammatory conditions, this epithelial layer integrity easily breaks down allowing pathogens to get access the body, the intestinal mucosa is also home of the largest immune system. The intestinal mucosa hosts numerous macrophages, dendritic cells and lymphocytes, contributing to the protection of the body from pathogen invasion [13]. Of special interest among these immune cells are the so-called intraepithelial lymphocytes (IELs). IELs are a unique population of pre-activated, yet resting, resident $\mathrm{T}$ lymphocytes located within the epithelial cell layer outside of the basal lamina of the intestinal mucosa [14]. As part of the Gut-Associated Lymphoid Tissue (GALT), this T cell population resides in close contact with the epithelial cells and the luminal content. Their main function is to maintain the intestinal barrier integrity and prevent pathogen invasion $[1,15,16]$. As local immune cells, they may present a first line of defense against pathogenic challenge and exogenous antigens before a slower antigen-specific immune response is induced [17]. Recent studies showed that localization of IELs along the villi is conditioned by the microbiota, and upon bacterial infection IEL respond dynamically with well-defined behavioral changes, including reduced vertical displacement, altered villus positioning, and increased interepithelial flossing movement from the basement membrane towards the lumen [16]. This mechanism enhances the access and proximity of IELs to pathogens during infection, permitting them to exert protective effects via induction of wound healing, as well as cytotoxicity in an IEC coordinated-manner [1, 15-17]. Though considered important, the role and regulation of IEL functions in the epithelium remain incompletely understood $[17,18]$.

Other immune cells of the GALT contributing to the intestinal immune regulation are the lamina propia lymphocytes (LPL), which together with IELs represent an immune effector site in the intestine. The inductive site of intestinal immune responses, on the other hand, are represented by mesenteric lymph nodes (MLNs), Peyer's patches, colonic patches and isolated lymphoid follicles. The combined action of intestinal inductive and effector sites coordinates efficient immune responses and ensures the maintenance and integrity of the intestinal epithelial barrier [19]. Thus, intestinal epithelial homeostasis and barrier functionality strongly depend on a well-balanced intestinal immune system [20].

All these specific cellular components and their complex regulation contribute to the fine-tuning of the intestinal epithelium barrier function, separating our organism from dietary components and luminal microbiota. Inflammatory responses within the intestinal mucosa are often associated with increased intestinal permeability due to loss of the integrity of the epithelial layer (Fig. 1). And when chronic, intestinal inflammation can lead to extra-intestinal autoimmune and inflammatory diseases, such as type-I diabetes, rheumatoid arthritis, and multiple sclerosis, among others [21]. In all these cases, an abnormal inflammatory process directly or indirectly affects the integrity and the function of the intestinal epithelium, highlighting the sensitivity of IECs to numerous immune cell-derived cytotoxic effector 


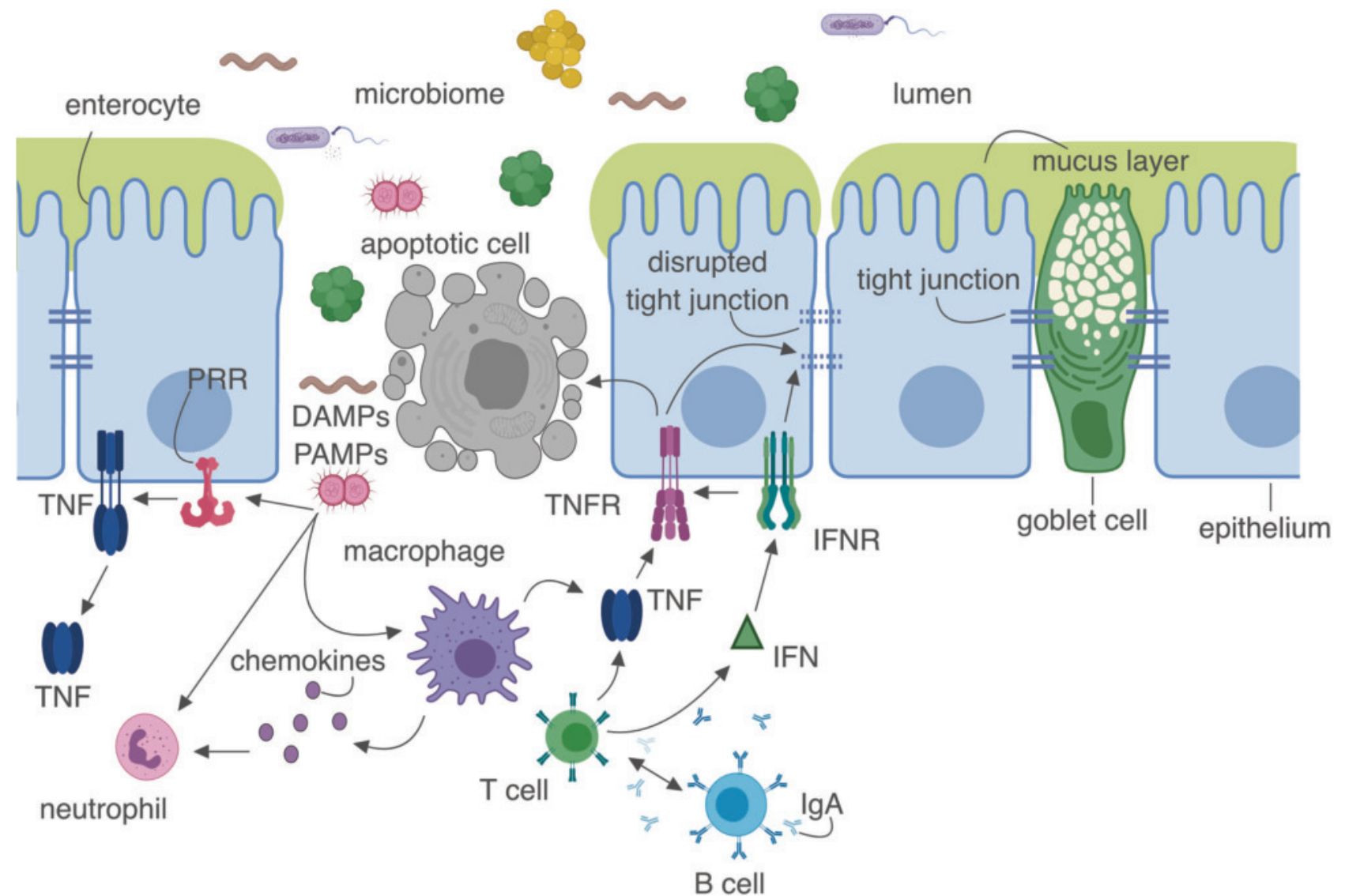

Fig. 1 Role of TNF in intestinal inflammation. Inflammatory responses within the intestinal mucosa lead to loss of epithelial layer integrity and increased permeability. Disruption of the epithelial barrier allows immune cells to get access to luminal content, a as well as associated danger-associated molecular patterns (DAMPs) and pathogenassociated molecular patterns (PAMPs). The activation of the immune system results in an inflammatory response and the

production of inflammatory cytokines, such as chemokines, TNF and interferons (IFN). IFN and TNF lead to tight junction disruption, whereas TNF may cause apoptosis in epithelial cells. The associated increased epithelial barrier permeability further fuels inflammatory processes and initiates a viscous cycle. When progressing into a chronic process, inflammatory bowel disease may develop. PRR pattern recognition receptor

molecules [8]. Once the epithelial integrity is lost, the increased exposure to bacterial and luminal antigens results in immune cell infiltration into the intestinal mucosa, likely aggravating cell death induction and damage by the release of cytotoxic effector molecules and pro-inflammatory cytokines. Thus, in this pro-inflammatory environment cytokines produced by infiltrating immune cells play a major role in the pathogenesis of intestinal inflammatory disorders. In this regard, there is strong evidence that members of the tumor necrosis factor (TNF) superfamily play a central role in the direct and indirect induction of epithelial damage. Especially TNF (Tumor Necrosis factor $\alpha$, TNFSF2) appears to be a major inflammation-promoting and tissue damage-promoting effector molecules during inflammatory pathologies [8, 20, 22], as supported by experimental mouse models of colitis [23, 24] and the astonishing therapeutic effects of TNF-neutralizing reagents in the treatment of IBD patients (reviewed in ref. [25]).

\section{TNF and TNF receptor molecules}

TNF is an extensively studied pro-inflammatory cytokine that presents a wide range of pleiotropic functions with implications in various cellular processes, including proliferation, differentiation, inflammation and cell death [20, 26]. Immune cells, such as monocytes, macrophages, activated natural killer (NK) and $\mathrm{T}$ cells, are the main sources of TNF. However, TNF is also produced by tissue cells of non-hematopoietic origin, i.e., fibroblast and epithelial cells [27]. TNF is synthesized as a $26 \mathrm{KDa}$ transmembrane precursor protein, that only after cleavage by a membrane-bound disintegrin metalloproteinase called TNF $\alpha$-converting enzyme (TACE/ADAM 17), it is liverated as a soluble $17 \mathrm{kDa}$ protein (sTNF) and able to form trimers [28, 29]. This soluble form is released from its cellular source and upon distribution by the circulatory system, may exert its activity at distant sites [25]. 


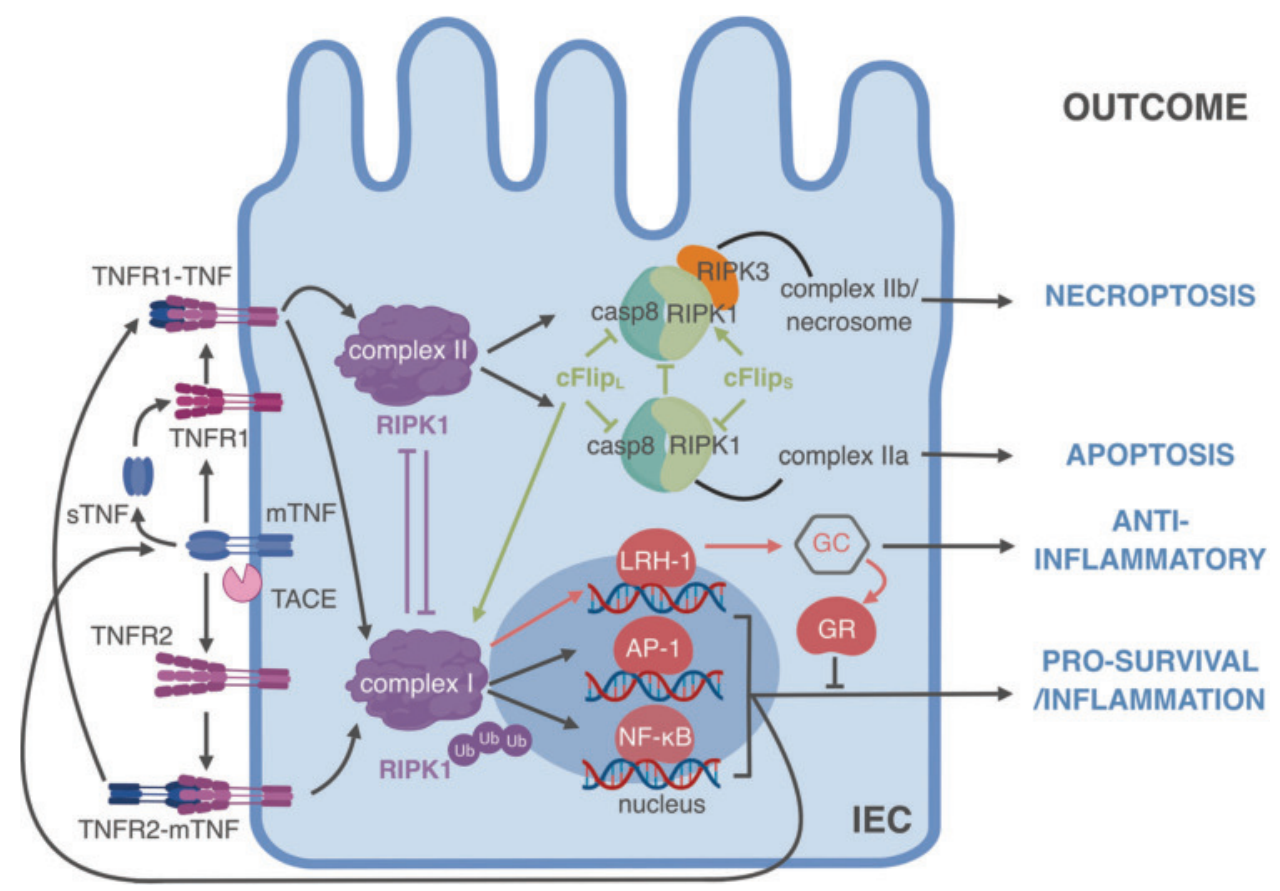

Fig. 2 TNF-dependent stimulation in intestinal epithelial cells can lead to inflammation, necroptosis, apoptosis, and immunosuppression. Intestinal epithelial cells express TNFR1 and TNFR2 that can be activated by soluble (sTNF) and membrane TNF (mTNF). Depending on the cellular context and the ubiquitination status of RIPK1, TNFR signaling may result in the formation of complex I or II. Complex I promotes a cellular pro-survival response by activating a series of transcription factors, such AP1 or NF- $\mathrm{KB}$, that render the cell less susceptible to cell death induction. This process occurs mainly by upregulating a series of anti-apoptotic proteins and pro-inflammatory

TNF binds to and stimulates two structurally related cell surface receptors $[30,31]$. These receptors are the TNF receptor (TNFR) 1 (TNFRSF1A/p55), expressed in all cells ubiquitously, and a larger receptor, the TNFR2 (TNFRSF1B/p75) that is expressed at low levels under steady-state conditions in some cell types of hematopoietic and endothelial origin $[32,33]$. However, the expression of both receptors can be induced by cytokines, such as interferons [34], potentially enhancing the stimulatory effect of TNF. This observation provides another layer of regulation for the observed synergistic effect between TNF and interferons, for example in disrupting the intestinal barrier function $[25,35,36]$. TNFR1 is a major driver of TNFinduced signaling pathways. Membrane-bound, as well as soluble TNF can stimulate TNFR1. TNFR2, on the other side, is preferentially activated by membrane-bound TNF [37]. This is likely related to a higher requirement of TNFR2 for receptor clustering by trans-membrane TNF in order to induce downstream signaling events. Noteworthy, trans-membrane TNF may not only activate TNFR on target cells, but also transduce revers signaling processes into the effector cell, a mechanism that has been suggested to cytokines. Activation AP-1 and NF- $\mathrm{KB}$ further induces TNF expression and associated positive feedback loops. In contrast, complex II formation promotes the cell to undergo apoptotic (complex IIa) or necroptotic (complex IIb) cell death, depending on the levels of cFLIP isoforms, caspase-8 activity and RIPK1 activity. Alternatively, TNF can trigger an LRH-1-regulated signaling pathway resulting in the synthesis of immunoregulatory glucocorticoids (GC). Activation of the glucocorticoid receptor (GR) suppresses TNF-induced inflammation and induces apoptosis in immune cells

contribute to co-stimulatory signals in immune cell activation. Trans-membrane TNF-mediated reverse signaling may also be involved in the mechanism of action of some antiTNF agents [38-40].

Cells expressing TNFR2 also express TNFR1 in ratios that are cell type-dependent [41]. As other members of the TNFR superfamily, both receptors present conserved $\mathrm{N}$ terminal cysteine-rich extracellular domain, but only TNFR1 contains a cytoplasmic region of $\sim 80$ amino acid residues that forms the so-called death domain (DD) [42, 43]. DD are highly conserved in all death receptors of the TNFR family (Fas/CD95, TNFR1, TRAILR1 and 2). However, different receptors recruit different adapter and signaling molecules via their DD [44]. In this regard, depending on the cellular context, TNF receptors are able to induce apoptosis, necroptosis, as well as pro-survival or pro-inflammatory pathways [45] (Fig. 2). Interestingly, while in most cell types TNF promotes activation signals resulting in pro-inflammatory responses, in the intestinal epithelium it causes cell death of mature IECs, promoting their detachment from the epithelial layer and resulting in a loss of epithelial barrier function [46, 47]. Of note, this 
direct cell death induction by TNF is predominantly mediated by TNFR1, as its deletion almost completely abrogates TNF-induced intestinal epithelial damage [48]. In contrast, TNFR2 has been typically related to induction of survival signals, and appears to offer protective roles in several pathologies, including autoimmune disease [41]. However, this dichotomy is being challenged by the existence of crosstalk between the two TNF receptors, resulting in contradictory findings [49] (further discussed in following sections).

\section{Complex-I and transcriptional pathways}

After stimulation by TNF, TNFR1 binds to and recruits the adapter protein TNFR-associated death domain (TRADD) via homotypic DD-DD interactions. This process does not require receptor internalization. After recruitment of different signaling molecules and a series of subsequent ubiquitylation events with different ubiquitin linkage chains, complex-I is formed. More specifically, complex I consists of TNFR1, TRADD, TNFR-associated factor-2 (TRAF2), E3-ubiquitin ligases cellular Inhibitor of Apoptosis Protein1 and 2 (cIAP1-2), the linear ubiquitin chain assembly complex (LUBAC: HOIL; HOIP and SHARPIN), and the serine-threonine receptor-interacting protein kinase 1 (RIPK1) [50, 51]. The mechanisms regulating the associated poly-ubiquitination events, and the specific role of different types of ubiquitin chains in TNFR1 signaling are not completely understood [52]. However, it is considered an important switch in the assembly of this complex since it allows the recruitment of the IKK complex (I- $\mathrm{BB}$ kinase $\alpha$, $\beta$, and $\gamma / \mathrm{Nemo}$ ), inducing $\mathrm{NF}-\kappa \mathrm{B}$ activation by catalyzing

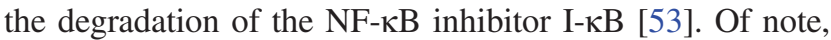
this ubiquitiylation process leading to $\mathrm{NF}-\kappa \mathrm{B}$ activation requires active repression by a series of de-ubiquitylases, such as A20/TNFAIP3 (TNF-induced protein 3) or CYLD, that in order to ensure only a transient and controlled TNF response, they are able to dismantle the ubiquitin network associated with complex-I (reviewed in ref. [54]). Thus, mice with IEC-specific deletion of A20 are highly sensitive to TNF-induced epithelial damage, suggesting a critical role of A20 in the regulation of TNF-induced cell death and survival [55]. Noteworthy, while systemic deletion of CYLD in mice results in autoimmunity and exacerbated intestinal inflammation [56], IEC-specific deletion of CYLD do not show spontaneous intestinal inflammation. However, these CYLD-deficient mice present a higher susceptibility towards inflammation-driven intestinal tumor development [57]. These results highlight the differences in TNF-induced $\mathrm{NF}-\kappa \mathrm{B}$ activation in cells from endodermal versus hematopoietic origin, as well as the complexity of the regulatory mechanism in the TNF signaling among different cellular types.

Once NF- $\kappa \mathrm{B}$ is active and translocates to the nucleus, it triggers a robust pro-survival response by the transcriptional regulation of numerous cytokines, as well as gene products that can counteract death pathways at different stages, such as cFLIP (cellular Flice-like inhibitory protein) or IAPs (reviewed by ref. [58]). Interestingly, $\mathrm{NF- \kappa B}$ is a relevant transcriptional regulator of TNF itself (reviewed in ref. [59]), resulting in an important auto-controlled mechanism of TNF production. Indeed, deregulated NF- $\kappa \mathrm{B}$ activation in the intestine results in massive inflammation and epithelial damage, highlighting the importance of this transcription factor in epithelial cell fate decision [13].

TRAF2 recruitment to the receptor complex is critical for TNFR1-induced activation of the mitogen-activated protein kinase (MAPK) pathways that can be grouped in three main kinase cascades: the extracellular signal-regulated kinases (ERKs), the c-Jun N-terminal kinases (JNKs), and the p38 MAP kinases (reviewed in ref. [60]). MAPKs activity relay on the sequential interaction and activation between members of a given cascade and can lead to the regulation of a variety of cellular outcomes, including proliferation, differentiation and cell death $[61,62]$. This regulation occurs mostly through the phosphorylation and further activation of a series of transcription factors, such as activator protein 1 (AP-1), p53 or c-Myc, among others [53, 63, 64]. But also, MAPKs-dependent post-translational mechanism can determine the signaling outcome, for instance by phosphorylation or by promoting the mRNA stabilization of specific targets $[61,65,66]$. On top of that, MAPKs are able to regulate positive and negative autocrine loops that feed into MAPK cascades activation, increasing the complexity and diversity of the MAPKs signaling outcome [61, 67]. Thus, the specific role of each kinase in the TNF signaling outcome remains incompletely understood and it is highly cell type-dependent and context-dependent (revised in ref. [64]). However, from a very simplified point of view, cell survival is usually linked with the activation of ERK1/2, while JNK and p38 are linked to induction of apoptosis [68]. In this line, in the absence of NF- $\mathrm{BB}$ activation cells with specific deletion of key components of the JNK pathway seems to be resistant to programmed cell death [69]. Different candidate substrates have been postulated as a JNK targets, mediating its pro-apoptotic response. Of note, activating protein (AP-1, Jun/Fos) is also a transcriptional regulator of TNF, as well as other genes involved in inflammation and cell survival, and contributes, together with NF- $\kappa \mathrm{B}$ activation, to the TNF-dependent signaling outcomes. Therefore, the interplay between MAPKs and NF- $\kappa \mathrm{B}$ activation is a key event that controls cell survival or cell death, and represents a crucial step to a 
wide range of biological processes, including $\mathrm{B}$ and $\mathrm{T}$ lymphopoiesis, adaptive immunity or oncogenesis [70, 71].

The above-described TNF-induced signaling pathways resulting in NF- $\kappa \mathrm{B}$ activation refers to the canonical NF- $\kappa \mathrm{B}$ pathway. However, in the absence of TRAF2 or IAPs, TNF stimulation allows the activation of the non-canonical or alternative activation of $\mathrm{NF}-\mathrm{\kappa B}$ via the MAP3K family member NF-кB-inducing kinase (NIK) [72, 73]. Briefly, the non-canonical pathway requires stabilization of NIK, which in turn phosphorylates and activates IKK $\alpha$, leading to the processing of NF- $\mathrm{KB} 2 / \mathrm{p} 100$ and the generation of the active p52 subunit. Together with the NF- $\kappa B$ subunit RelB, it forms an active transcription factor complex [72, 74-76]. Thus, the rapid degradation of NIK is a key event in the regulation of the non-canonical $\mathrm{NF}-\kappa \mathrm{B}$ pathway in resting cells, preventing its constitutive activation [77, 78]. Since NIK-deficient mice show no obvious defects in TNFstimulated NF- $\kappa \mathrm{B}$ activation, the relevance of NIK in mediating TNF-dependent effects in the intestine in vivo is being questioned [79]. Therefore, it seems clear that activation of the canonical NF- $\mathrm{NB}$ pathway is the primary response to TNFR1 stimulation in most tissues, and noncanonical NF- $\kappa \mathrm{B}$ activation only takes place under special circumstances, for instance in the absence of RIPK1 [78].

\section{Complex-II and the cell death mechanism}

While complex-I is the fast primary response upon TNF stimulation associated with pro-survival responses, complex-II assembles more slowly as a secondary event and drives cell death pathways [52] (Fig. 2). The main events leading to complex-II formation are the TRADD dissociation from the receptor and its association with the adaptor molecule FADD (Fas-associated protein with death domain). The kinetic and molecular requirements for this process are still incompletely understood [80]. However, FADD appears to be critical for the recruitment of the cysteine protease pro-caspase- 8 and its close homolog and inhibitor cFLIP (cellular FLICE-inhibitory protein). This protein complex is called complex-IIa, and it is able to promote caspase-8 activation and caspase-8-dependent apoptotic cell death $[50,53,80,81]$.

While under certain circumstances also pro-caspase-10 is recruited to complex-IIa, its role in most of the apoptosis scenarios is not clear $[82,83]$. In contrast, the presence and abundance of cFLIP in complex-IIa defines the signaling outcome upon TNF stimulation [50, 84, 85].

cFLIP is a proteasome-regulated short-lived protein and a good inhibitor of death receptor-induced apoptosis [86]. cFLIP competes with pro-caspase- 8 for binding to its FADD-dependent activation platform [87]. Depending of the cFLIP isoforms recruited to this platform, different outcomes take place. While the short isoform of cFLIP $\left(\mathrm{cFLIP}_{\mathrm{S}}\right.$ ) blocks activation of pro-caspase-8, the long isoform is able to partially support caspase- 8 activation by hetero oligomerizing with caspase- 8 , resulting in partial cleavage [88, 89]. In this stage, caspase- 8 has limited catalytic activity, however with critical regulatory functions. Caspase- 8 is still able to cleave RIPK1, removing its kinase domain and thereby preventing its kinase activity [90]. On the other hand, it can also cleave $\operatorname{cFLIP}_{\mathrm{L}}$, allowing the generation of the cFLIP p43 and p22 cleavage fragments, which help to induce the NF- $\kappa \mathrm{B}$ pathway by binding to the IKK complex [91-93]. Therefore, presence of $\mathrm{cFLIP}_{\mathrm{L}} / \mathrm{cas}-$ pase- 8 hetero-dimers results in partially activated caspase- 8 , preventing an alternative caspase-independent cell death (discussed below in more detail), while favoring gene transcription and inflammation. Interestingly, NF- $\mathrm{KB}$ activation has been shown to up-regulate $\mathrm{CFLIP}_{\mathrm{L}}$ levels, while down-regulating $\mathrm{cFLIP}_{\mathrm{S}}$ [94]. This appears to represent an amplification loop since $\mathrm{cFLIP}_{\mathrm{L}}$, but not $\mathrm{cFLIP}_{\mathrm{S}}$, is able to bind TRAF2 and RIPK1, resulting in further NF- $\kappa$ B activation [95]. In contrast, stress signals such as TNFdependent JNK activation, have been shown to cause the proteasomal degradation of $\mathrm{CFLIP}_{\mathrm{L}}$, favoring TNF-induced cell death induction [96]. In the intestinal epithelium, cFLIP regulation of the TNF pathway appears of special relevance since its intestine-specific deletion results in spontaneous TNFR1-induced IEC apoptosis, leading even to perinatal lethality in mice [97]. Interestingly, higher levels of cFLIP $\mathrm{L}_{\mathrm{L}}$ protein have been detected in tissue samples from IBD patients, suggesting a TNF-induced up-regulation of $\mathrm{CFLIP}_{\mathrm{L}}$ as an attempt to inhibit TNF-dependent apoptosis [98].

Altogether, cFLIP levels define the formation of complex-IIa, i.e., high FLIP $_{\mathrm{L}}$ levels inhibit transient formation of complex-IIa, whereas low levels of $\mathrm{cFLIP}_{\mathrm{L}}$ result in caspase-8-dependent apoptosis. Of interest, low levels of cFLIP $_{S}$ also result in higher susceptibility to TNF-induced IEC apoptosis, however, higher levels may even result in of the deviation of the cell death pathway towards a caspaseindependent cell death called necroptosis (discussed below) (Fig. 2). Therefore, considering that caspase-8 levels appear more stable, it seems feasible that small variations of cFLIP concentrations may determine whether a cell might die or survive in a given situation [94]. This fact seems to be of special relevance in the intestinal mucosa, where cFLIP has been shown to represents a major switch in the regulation of survival and tissue homeostasis [97].

A third complex, complex IIb or the necrosome, with many similarities to the previous ones, may also be formed upon TNF stimulation [99] (Fig. 2). In this case, the cytosolic FADD/caspase-8/cFLIP complex binds in a TRADDindependent manner to a stable, but de-ubiquitylated form of RIPK1. Additionally, the RIPK1 family member RIPK3 (the receptor-interacting protein kinase 3 ) is able to bind to 
this complex via RIPK-homotypic interaction motifs, which are essential for this cell death induction [99-102]. This complex formation results in a mode of cell death called necroptosis, which is independent of caspase activation but requires kinase activity [103]. Therefore, when caspase- 8 activation fails, or it is inhibited due to the high levels of cFLIP $_{S}$ or caspase inhibitors, caspase-8-dependent cleavage of RIPK1 is prevented, allowing the association of RIPK1 and RIPK3 and the activation of MLKL (mixed lineage kinase domain-like pseudokinase)-dependent necroptosis [104]. This process results in the rupture of the plasma membrane and necrosis-like cell death. Caspase activation prevents necroptosis also by other means. For instance through caspase-8-dependent RIPK3 [105] or CYLD [106] cleavage. CYLD de-ubiquitylates RIPK1, and thus favors the formation of the necrosome [107]. Indeed, inflamed tissues from patients with IBD present lower levels of caspase-8 [108], but high levels of TNF, suggesting that TNF-induced necroptosis may contribute to the damage of the intestinal epithelium in these patients. In addition, IECspecific deletion of caspase- 8 or FADD causes excessive inflammation and increased epithelial erosion, partially in a microbiome-dependent manner. Of note, this form of IEC death and inflammatory process can be rescued by RIPK3 deletion, providing experimental evidence that IEC necroptosis contributes to epithelial damage, at least under these circumstances [100, 109, 110]. Interestingly, in the caspase-8-deficient or FADD-deficient epithelium, Paneth cells appear to be particularly sensitive to necroptosis induction, yet an underlying explanation still remains elusive [9]. Nevertheless, substantial differences could be observed in the phenotype of animals with IEC-specific caspase- 8 or FADD deletion. While mice lacking FADD develop inflammation and increased epithelial damage in both, small and large intestine, in caspase-8-deficient animals only the small intestine is affected. This observation suggests a different role of caspase- 8 in controlling epithelial cell death and inflammation in the intestine, independently of its proteolytic activity [9]. In line with these findings, a recent report highlights the non-enzymatic role of caspase- 8 in the TRAIL (TNF-related apoptosis-inducing ligand) receptor-induced cytokine/chemokine production in a FADD/RIPK1-dependent manner [111]. Thus, it seems feasible that a similar mechanism might take place upon TNFR1 and/or TNFR2 stimulation. Of interest, lack of TNF in mice with epithelial-specific FADD deletion strongly ameliorates colitis, highlighting the role of luminal bacteria in triggering TNF-dependent intestinal inflammation. However, Paneth cell loss and enteritis remain unaffected [110]. Along these lines, reduced degradation of cFLIP was observed in some IBD patients, suggesting an increased caspase inhibition and necroptosis induction in IECs from those patients [112]. This fact seems to further support a role of necroptosis in the pathogenesis of intestinal inflammatory disorders. However, it is presently unclear whether complex-IIb/necrosome originates from an inactive complex-IIa or it forms in parallel [52]. Although a pathophysiological relevance of this process has been suggested, e.g., in viral infections, IBD, pancreatitis or ischemiareperfusion injury (reviewed in ref. [100]), little evidence is available whether TNF administration in vivo directly promotes IECs necroptosis or whether apoptosis is the predominant form of IEC death.

Deletion of RIPK3 has been established as the gold standard in order to prevent and prove necroptosis-induced cell death [103, 110, 113]. However, recent in vitro studies showed that RIPK3 contribute also to TNF-induced RIPK1dependent apoptosis, independently of its RHIM domain and kinase activity [114]. Thus, caution should be taken when drawing conclusions regarding the unique requirements of RIPK3 in necroptosis induction. Yet, the biological relevance of this observation remains to be further explored. Nonetheless, RIPK3-deficient mice fail to undergo TNF-dependent epithelial barrier disruption, at least implying an inhibition of TNF-dependent necroptosis and suggesting a relevant role of this mode of cell death in the pathogenesis of intestinal inflammatory disorders [115, 116]. However, only combined deletion of caspase- 8 and RIPK3 resulted in complete protection of TNF-induced damage, suggesting that the observed tissue -damage is mediated by a combination of apoptosis, necroptosis and/or inflammation [116]. Interestingly, IEC-specific deletion of RIPK1 triggers a severe intestinal pathology due to excessive caspase-8/FADD-dependent IEC apoptosis [117, 118], and associated increased inflammatory responses due to the breakdown of the intestinal epithelial barrier function [117]. Under these circumstances, caspase- 8 deficiency, but not RIPK3 deletion, completely blocked the inflammatory and apoptotic phenotype of IEC-specific RIPK1 deletion [117]. Similarly, the lack of RIPK1 in combination with deletion of caspase- 8 or FADD, resulted in a surprisingly increased intestinal epithelial damage, suggesting that RIPK3 induces RIPK1-independent IEC death in the absence of caspase- 8 or FADD [118].

RIPK1 appears to be involved in various TNFR1induced signaling processes. However, its kinase activity is not essential for the induction of all these pathways. While the RIPK1 kinase activity does not seem to be required for NF- $\mathrm{BB}$ activation, it is crucial for necroptosis induction and, in some cases, for caspase activation [80, 119]. Nevertheless, and as opposed to the complete RIPK1 knockout mouse, the kinase activity of RIPK1 seem to be dispensable for the maintenance of the epithelial homeostasis, since mutant mice with a defective RIPK1 kinase activity show no sign of spontaneous inflammation or apoptosis $[115,117,118,120]$. Worth of notice is the fact 
that RIPK1-deficient cells reconstituted with a pointmutated RIPK1 that prevents its kinase activity (RIPK1K377R), showed higher sensitivity towards TNF-induced cell death, even under conditions of NF- $\mathrm{KB}$ impairment and far more than those reconstituted with wild-type RIPK1 [121]. These observations imply that the RIPK1 kinase activity might serve as an additional pro-survival mechanism that prevents the cell death induction, independently of $\mathrm{NF}-\kappa \mathrm{B}$ activation. However, further experiments need to be performed in order to elucidate the specific requirements for such a regulation. Of note, conclusions from studies based on these point mutations might be drawn with caution, since these specific point mutations altering kinase activity might also alter protein binding preferences and ubiquitylation, therefore affecting the overall outcome of TNF signaling at different levels.

Interestingly, the role of RIPK1 kinase activity is not identical to that of RIPK3 kinase activity in all TNFtriggered cell fate decisions. For instance, RIPK3 kinase mutant knock-in mice showed signs of RIPK1/FADD/caspase-8-mediated apoptosis during embryogenesis, thus, further confirming a role for RIPK3 kinase activity in suppressing apoptosis during embryonic development [100, 122].

Altogether, these results highlight the relevance of the RIPK1-caspase- 8 node in the IECs fate decisions, thus changes affecting their stability, structure, or activation status can have devastating consequences for tissues with a highly inflammatory milieu and a TNF-rich environment, like is the case of the intestinal epithelium.

\section{Regulatory checkpoints in TNF signaling}

TNF-induced IEC death has been established as a complex signaling pathway with relevance in mostly pathophysiological scenarios. Deciphering the specific molecular events after TNF receptor activation leading to tissue damage may result in clinical benefits for the treatment of common inflammatory disorders. This is particularly true for TNFinduced intestinal epithelial damage. Although most of the key proteins and their regulatory functions in TNF signaling has already been discussed, two "checkpoint" events with special relevance for the fate of IECs will be outlined in more detail.

Upon TNF stimulation, NF- $\kappa \mathrm{B}$ activation and associated robust pro-inflammatory response have been thought to be the main mechanism in most tissues that counteracts the cell death pathways. Nevertheless, under specific circumstances where certain checkpoints are disrupted, TNF stimulation can also result in cell death, as discussed above. Interestingly, recent findings suggested that these TNF checkpoints

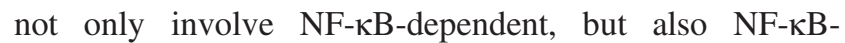

independent mechanisms, regulating the susceptibility of a given tissue to undergo TNF-induced cell death [121].

The NF-кB-dependent checkpoints have been already discussed to some extend and involve the transcriptional regulation of certain anti-apoptotic proteins, such as cFLIP [94], TRAF1/2 or IAPs [123], as well as other targets counteracting TNF-induced cell death elsewhere in the cell death pathways. In all of these cases, a transcriptiondependent genetic programing renders the cells more resistant to the cell death pathways. Of note, this transcriptional regulation occurs downstream of the formation of TNFR complex-I [52]. Since stimulation with TNF does not lead to cell death in most tissue unless NF- $\mathrm{BB}$ signaling is blocked [124], it is easy to speculate that the capacity of a cellular system to form and maintain the assembly of complex-I leading to NF- $\mathrm{BB}$ activation might be key in order to determine the susceptibility of a given tissue to undergo TNF-dependent cell death. However, blocking NF$\kappa \mathrm{B}$-dependent transcriptional regulation with the stable transfection of the non-degradable NF- $\kappa \mathrm{B}$ inhibitor I $\kappa \mathrm{B} \alpha \mathrm{SR}$ did not impair TNF-induced cell death signaling [121]. This fact suggests the existence of an early pro-survival signal, independent on the $\mathrm{NF}-\kappa \mathrm{B}$ pathway, that regulates cell fate decisions.

NF- $\kappa \mathrm{B}$-independent checkpoints do not relay on transcriptional regulation but depend on the presence and status of RIPK1 [121] (Fig. 2). For instance, the polyubiquitylation status of RIPK1 represents a potential break in the TNF-induced cell death pathways. Polyubiquitylation of RIPK1 prevents its association with caspase- 8 and subsequent cleavage, leading to a deviation of the pathway towards NF- $\mathrm{BB}$ activation [121]. O'Donnell and colleagues [121] also observed that unlike wild-type RIPK1, the RIPK1 kinase mutant (RIPK1-K377R) was able to form a complex with caspase-8, implying a role for the kinase activity in the regulation of the RIPK1-caspase- 8 association. In line with these findings, absence of RIPK1 ubiquitin-modifying enzymes, such as the deubiquitylase CYLD [57], IAPs [48] or the LUBAC complex member SHARPIN [120], results in higher susceptibility towards TNF-induced cell death, and/or spontaneous inflammation and tissue disruption. Surprisingly, mice with cIAP1, but not cIAP2 or XIAP, deletion are more susceptible to TNFinduced IEC death. However, none of these animals develop spontaneous colitis, suggesting that single IAPs deletion might not result in the chronic activation of the NF$\kappa \mathrm{B}$ pathway, either via the non-canonical pathway or endogenous TNF production, probably due to compensatory mechanisms [48]. Nevertheless, specific cIAP1dependent, but not cIAP2-dependent effects might have greater outcomes in the formation of complex-I respect to the other complexes, reducing the probability of the system to favor TNF-induced cell death. Along these lines, specific 
loss of K63-linked ubiquitylation on RIPK1 has been shown to result in a pro-death signal in TNF-stimulated cells [121]. Another potential contribution might be the cIAP1-dependent TRAF2 degradation [125], since TRAF2 loss-of-function has also been shown to potentiate TNF-cell death in a RIPK1-dependent manner [121].

Overall, RIPK1 represents a signaling molecule with a dual role in the intestinal epithelium, and depending on its poly-ubiquitylation status, RIPK1 is able to mediate either cellular survival or demise. Yet it is currently not fully clear which specific RIPK1 modifications distinguishes between TNF-induced necroptosis versus apoptosis, and if this differences in cell death mechanism could be of relevance in clinical applications, for instance in cancer treatment, where apoptosis induction may result in a less favorable outcome than necroptosis induction [126].

Although ubiquitin modifications of RIPK1have been established as important checkpoints, additional regulatory mechanisms subsequent to this modification have been shown to be of relevance in the TNF signaling. For instance, different phosphorylation events are critical in preventing RIPK1-dependent apoptosis, without affecting the RIPK1 ubiquitylation status [52]. This is evident in mice with intestinal-specific deletion of proteins associated with complex-I, such as TAK1 (transforming growth factor- $\beta$ activated kinase 1 , a MAP3K in the JNK and NF- $\mathrm{KB}$ pathway [71]), NEMO/IKK $\gamma$ or IKK $\alpha / \beta$ [127-130]. Besides specific phenotypic differences regarding the degree and spontaneity of the intestinal erosion and inflammation associated with these gene deletions, in all these cases TNF was found to be a critical executioner of this RIPK1dependent cell death [13]. Although their NF-кB-dependent contribution to the complex-I regulation in those models should not be excluded, in vitro studies reveal also a prosurvival function of these molecules, independently on their roles in $\mathrm{NF}-\kappa \mathrm{B}$ activation [52]. TAK1 kinase activity has been shown to regulate the susceptibility of cells to undergo TNF-induced RIPK1-dependent apoptosis independently of $\mathrm{NF}-\kappa \mathrm{B}$, probably by modifying directly or indirectly the RIPK1 kinase activity [131] and without affecting RIPK1 ubiquitylation [114]. These results confirm the existence of a regulatory checkpoint in RIPK1-dependent cell death, even in the absence of its regulation by poly-ubiquitylation. Similar results were found for NEMO. Its pro-survival activity, independently of NF- $\mathrm{KB}$ activation, appeared to relay on its ability to associate with RIPK1. This in turn prevents the RIPK1-caspase-8 association, and thus negatively regulates TNF-mediated RIPK1-dependent complexII formation and cell death [132]. In addition, absence of IKK $\alpha / \beta$-mediated phosphorylation of RIPK1 after ubiquitylation has been shown to promote the assembly of complex-II, thereby sensitizing cells to a RIPK1-dependent cell death [133]. Altogether, these results suggest that RIPK1 phosphorylation regulates its pro-death activity in a step that is downstream to its own ubiquitylation, thus adding an extra regulatory layer in TNF-mediated cell death.

Interestingly, these studies suggest that events affecting the early checkpoint will affect also checkpoints further downstream in the pathway. The question remains though, whether signals favoring RIPK1-dependent cell death are sufficient to execute TNF-induced cell death or whether down-regulation of the NF- $\kappa \mathrm{B}$ pro-survival pathway is additionally required [52]. Further in vitro and in vivo studies will help to clarify this interplay between $\mathrm{NF}-\kappa \mathrm{B}-$ dependent and independent checkpoints in order to help to predict and counteract the TNF-dependent outcome in the different cellular context.

\section{TNFR2-induced signaling processes}

As previously discussed, cellular fate in response to TNF, i.e., cell death versus cell survival, is critically defined by the quality and nature of the signaling protein complexes recruited to the TNFR1 [80, 134, 135]. TNFR2, on the other hand, lacks DDs and therefore cannot bind TRADD. However, it is still able to trigger the TNF signaling by TRAF2-association, thus activating classical and alternative NF-кB pathways [136, 137]. Although the molecular pathways triggered by TNFR1 and TNFR 2 seem quite established, controversy still exists regarding the contribution of TNFR2-mediated effects to the TNF-dependent cytotoxicity. For instance, the role of TNFR 1 and TNFR 2 in the different murine colitis models is still poorly understood. While TNFR1-deficiency seems to exacerbate the DSS (dextran sodium sulfate)-induced inflammatory condition and subsequent epithelial damage by increasing the production of pro-inflammatory cytokines, the lack of TNFR2 attenuated the severity of the disease [138]. Opposite is the effect of TNF-R1 deletion in mice after TNBS (trinitrobenzenesulfonic acid) exposure. In this case, lack of TNFR1, but not TNFR2, resulted in reduced colitis induction and tissue damage [139]. Finally, while in a model of adaptiveT cell transfer-induced colitis the absence of TNFR2 signaling in the non-lymphoid cells of the recipient mice did not attenuate the course of the disease, lack of TNFR2, but not TNFR1, in the transferred $\mathrm{T}$ cells reduced the pro-inflammatory profile, improving significantly the diseases outcome [140, 141]. However, similar studies also exist that contradict these findings [141]. Thus, differences in the mouse strain used, intestinal microbiome or the differences in the molecular mechanism leading to the disease progression among these models, might explain these apparently contradictory roles of TNFRs in the TNF-dependent inflammation and cell death mechanisms. Of note, the use of systemic TNFRs-deleted 
mice might add another level of complexity to the problem, since it increases the difficulty to distinguish between the contributions of the TNF signaling in immune cells from that in other cell types [141].

In vitro studies using TNFR2-specific ligands suggested that TNFR2 potentiates the cytotoxic effect of TNFR1 in a cell-type dependent manner, while it exhibits no cytotoxicity by itself $[142,143]$. Interestingly, TNFR2 activation has been shown to induce a transient TRAF2 degradation in some cells lines that can be counteracted by TNFR1induced TRAF1 up-regulation [49, 144]. Although the mechanism is not clear, this degradation has been shown to be independent of cysteine protease activities, but dependent on the cIAP1-mediated proteasomal degradation [125]. Another study reports a role for A20 in mediating TRAF2 lysosomal degradation, suggesting an alternative cIAPindependent mechanism [145]. Since TRAF2 is required for TNF-induced JNK activation, this degradation process suggests a somehow regulatory mechanism for the termination of JNK activation, while favoring the activation of $\mathrm{NF}-\kappa \mathrm{B}$. Considering the potential pro-apoptotic role of JNK, this fact could explain the decreased sensitivity of TNFR2-deficient mice to TNF-induced cell death [146]. In line with these findings, mice lacking TNFR2 present dramatically increased endotoxin-induced TNF levels in serum, suggesting an enhanced TNFR1-dependent inflammatory response [147]. However, the inhibition of TNFdependent cell death upon TNFR2 deficiency could be observed only after TNF-stimulation in the presence of transcriptional inhibitors, thus with impaired NF- $\mathrm{\kappa B}$ activation, or additionaly, after TWEAK (TNF $\alpha$-like weak inducer of apoptosis) stimulation [144, 145]. TWEAK exerts its biological activity by activating Fn14 (fibroblast growth factor-inducible-14), which like TNFR2, is a TRAF2-interacting receptor of the TNFR superfamily [148]. This TWEAK/Fn14 system has been shown to exert its cytotoxicity by two main mechanisms; (i) by cell typespecific induction of TNF and subsequently activation of TNFR1, or (ii) by depletion of the protective TRAF2-cIAPs complexes and thus limiting their availability to TNFR1 [149-151]. Interestingly, TNFR2 has been suggested to elicit cytotoxic activity by similar mechanisms as the TWEAK/Fn14 system [152]. Indeed, at least in macrophages, TNFR2 has been shown to enhance TNFR1dependent cell death by up-regulating TNF levels [136, 142]. Thus, the combination of TNFR 2 and TWEAK stimulation seems to further enhance the depletion of TRAF2cIAPs complexes, promoting TNF-dependent cytotoxic pathways. However, it remains still unclear how important these pathways are in cells of non-hematopoietic origin.

All in all, further studies are required in order to clarify the specific molecular mechanism(s) that regulate the crosstalk between different TNFRs in the different cellular environments. For instance, which are the molecular requirements that promote TNFR2-dependent cytotoxicity and which TNFR1-dependent events are critical for potential clinical interventions in inflammatory diseases. Despite the complex interplay between TNFR1 and TNFR2 pathways in TNF-dependent inflammatory disorders, TRAF2 seems to be an important regulator of the TNF signaling. Along these lines, potential strategies for pharmacological targeting of TRAF2 activation are considered for the treatment against intestinal inflammatory diseases [144].

\section{TNF in intestinal inflammatory disorders}

In the intestinal epithelium, TNF exerts a broad spectrum of activities, including regulation of inflammation and cell death, as well as the migration of IECs during intestinal wound-healing responses [20]. Considering the complexity of TNF signaling and its relevance in these processes, excessive exposure to this cytokine may result in a series of events affecting the overall intestinal barrier function, even in some cases with devastating consequences. For instance, acute TNF exposure has been shown to induce excessive IEC shedding leading to discontinuities or gaps in the epithelial layer [153]. In addition, TNF treatment leads to changes in the expression levels of some mucins, as well as TNFR1-dependent loss of goblet cells, thereby directly and indirectly affecting the integrity of the intestinal mucosa [154]. TNF has also a direct effect on the expression and organization of TJ proteins, resulting in loss of TJ functions, increased epithelial permeability and the induction of an inflammatory response [155]. Interestingly, these features have also been broadly associated with intestinal inflammatory pathologies, such as IBD [156].

IBD comprises a group of inflammatory disorders of the gastrointestinal track that has been associated with host genetics, imbalanced luminal microbiome and deregulated host immune responses. IBD is characterized by a persistent intestinal inflammation associated with severe epithelial damage caused by abnormal immune responses to the intestinal microbiome [157, 158]. The two most dominant disease entities of IBD are Crohn's disease (CD) and ulcerative colitis (UC). While CD is characterized by patchy inflammatory sections along the entire gastrointestinal tract [7], UC is a heterogeneous group of diseases characterized by a continuous inflammation of the colonic lamina propria [159].

TNF is considered one of the most important effector molecules in the pathogenesis of IBD [160, 161]. As discussed above and suggesting a somehow shared mechanism of action, experimental deletion of different genes involved in the TNF signaling results in pathologies resembling IBD 
in humans, including excessive intestinal inflammation and epithelial cell death. Hence, experimental mouse models of IBD are often associated with defects in the NF- $\kappa \mathrm{B}$-activation pathway and/or spontaneous IEC death, leading to deregulated immune responses [162]. In this line, deregulated TNF signaling is often associated with disease progression in IBD patients [41]. Furthermore, polymorphisms in TNFR1 and TNFR2 have been identified in patients with CD and UC [163-166] and TNFR2 is frequently upregulated in LP lymphocytes from patients with CD [167].

TNF plays an important role in the interaction and communication between immune cells and IEC. Excessive immune cell activation and associated TNF production has been shown to be a key event in intestinal inflammation [168]. Defects in the intestinal immune homeostasis lead to a vicious cycle, which promotes the chronification of intestinal inflammation and cell death. CD was historically associated with increased production of TNF by LP lymphocytes [169]. However, results from mouse models of colitis induced by adaptive transfer of colitogenic $\mathrm{T}$ cells, surprisingly demonstrated a critical role on the TNF production by non- $\mathrm{T}$ cells in recipient mice, rather than TNF from transferred $\mathrm{T}$ cells $[23,27]$. Yet, likely different source of TNF might contribute to the overall pathogenic role of TNF during experimental colitis in mice, and IBD in human patients.

The disease-promoting role of TNF in various inflammatory diseases, and IBD in particular, has been recognized since a long time and has resulted in the development of very successful TNF-targeting drugs (reviewed in ref. [25]). Up to date, different anti-TNF agents have been developed that, by binding to soluble and membrane TNF, are thought to prevent TNFR activation and the triggering of downstream signaling pathways. Apart from direct neutralization, anti-TNF antibodies may also have an impact on cell-cell interactions by binding and masking trans-membrane TNF on immune and epithelial cells. Furthermore, it has also been suggested that crosslinking of trans-membrane TNF by antibodies may induce the so-called reverse signaling effect into the TNF-expressing cell, resulting in regulatory processes [40]. Finally, other anti-TNF drugs are not only based on their capacity to neutralize TNF, but also on their ability to antagonize Fc receptor-expressing cells and their capacity of initiating and modulating immunocyte functions $[25,170]$. It is worth noticing that, besides the development of anti-drug antibodies by the host's immune system that can limit the efficacy of the therapy [25], anti-TNF agents can promote the development of other malignancies, due to their immunosuppressive function. This includes a higher risk of serious infectious complications, autoimmunity, lymphoma development, abnormal liver function or even neurological disorders, among others [171]. Therefore, the risk-benefits analysis prior to the application of this type of therapies is complex and requires a complete evaluation of the patient-specific circumstances and risk-profile in order to assure a successful treatment [172].

One of the first drugs targeting TNF is Infliximab (IFX, trade name Remicade), a humanized (25\% murine and $75 \%$

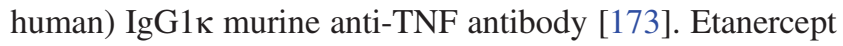
(ETA, trade name Enbrel) is a human TNFR fusion protein, which can bind sTNF and mTNF, thus capable of neutralizing TNF and to trigger revers signaling, however with apparently lower affinity to mTNF than IFX [38]. ETA was approved in 1998 and it comprises the extracellular region of human TNFR2 as a fusion protein with a C-terminal human IgG1 crystallizable fragment (Fc) domain [174]. Other TNF-targeting drugs are Golimumab (GOL, trade name Simponi), a fully humanized IgG1 anti-TNF with an Ig Fc identical to IFX but different Ig Fv sequence [175], or Certolizumab pegol (CERT, trade name Cimzia), a PEGylated humanized TNF antibody Fab fragment engineered to bind to TNF without crosslinking Fc receptors on effector cells [25, 176].

All above-mentioned antibodies are approved and licensed for therapeutic use in human inflammatory diseases, including UC and CD. Although they are generally well tolerated with relative minor adverse effects, not all current anti-TNF agents share the same properties and efficacy in the treatment of IBD. These differences are based on their structural properties that affect their mechanism of action. For instance the preferential binding to mTNF, hence capacity to induce revers signaling, or the presence or absence of Fc-binding regions, can greatly influence the efficacy of a given anti-TNF agent [25]. It is thus not surprising that, based on these differences, some drugs performed better in specific clinical trials than others, suggesting that some modes of actions may be more important than others. Of note, based on results from clinical trials, as well as mouse models, the neutralization of mTNF, rather than STNF, seems to be critical in the successful therapy of IBD [177, 178]. Moreover, differences in delivery method or half-life in plasma, e.g., enhanced by PEG-modifications [179], also affect drug efficacy in inflammatory disorders, such as IBD [25].

While TNF-targeting antibodies or receptor fusion proteins had and still have a terrific success in the treatment of UC and CD, some IBD patients do not respond to the antiTNF antibodies [25]. Therefore, alternative therapies are necessary for these patients to control intestinal inflammation. In this regard, a better understanding of the TNF signaling pathways and their exact role in the pathogenesis of intestinal inflammation may help to develop more specific therapeutic approaches. 


\section{Anti-inflammatory effects of TNF in the inestine: role of local glucocorticoid synthesis}

The pro-inflammatory role of TNF in the pathogenesis of IBD has been widely acknowledged. However, there is increasing evidence emerging that TNF may also have various anti-inflammatory properties [180]. In particular, its anti-inflammatory role in intestinal mucosa becomes more and more recognized. An interesting example in this regard is the role of TNF in DSS-induced colitis in mice. While in many models of colitis (e.g., transfer colitis and TNBSinduced colitis), TNF is a disease-promoting cytokine, often even required for disease induction, the pathology associated with the DSS colitis-model proceeds in the absence of TNF, and it is even accelerated in TNF-deficient mice [181].

Some of the anti-inflammatory properties can be specifically attributed to the role of TNF in the modulation of immune cell death $[182,183]$. In this regard, TNF sensitizes $\mathrm{T}$ cells to undergo apoptosis during inflammation, resulting in accelerated resolution of the inflammatory response [184].

More recently, Noti and colleagues [185, 186] identified a novel role for TNF in suppressing inflammatory responses in the intestine via the induction of local glucocorticoids synthesis in the epithelium (Fig. 2). Glucocorticoids (GCs) are steroid lipid hormones synthesized from cholesterol via a cytochrome P450 enzymes-dependent process. The adrenal glands are the main source of endogenous GCs, and adrenal GC synthesis is critically regulated by the hypothalamus-pituitary adrenal axis in response to physical, emotional and immunological stress. GCs exert their biological functions through the binding to their cognate receptor, the glucocorticoid receptor (GR). The GR is kept inactive in the cytoplasm under steady-state conditions, but translocates to the nucleus in order to initiate a variety of processes, such as the regulation of glucose metabolism, cell cycle progression, blood pressure and antiinflammatory processes [187]. In particular, the antiinflammatory activities of GCs are widely used in the treatment of inflammatory diseases, including IBD. While the adrenal glands are the predominant source of GCs in our body (adrenalectomy almost completely eliminates systemic GC levels), there is accumulating evidence that local extraadrenal GC synthesis in different tissues contributes to the regulation of tissue-specific processes. Thus far, thymus, lung, vasculature, skin, and intestinal mucosa have been recognized as GC-synthesizing tissues [188, 189]. Our lab has been the first one to describe the synthesis of immuneregulatory GCs in the intestinal mucosa [190]. We could identify the proliferating and stem cell zone in the intestinal crypts as the main source of intestinal GCs [191]. This is especially remarkable as cell cycle progression was found to closely regulate GC synthesis in these crypt cells, most likely through a series of cell cycle-dependent phosphorylation events [190]. An important potential target of phosphorylation-dependent activity regulation is certainly the nuclear receptor and transcription factor LRH-1 (Liver Receptor Homolog-1, NR5A2) [191]. While steroidogenesis in the adrenal gland is critically regulated by the nuclear receptor SF-1 (steroidogenic Factor-1, NR5A1), SF-1 is absent in the intestinal epithelium. In contrast, it seems to be functionally replaced by its close homolog LRH-1, which binds to identical consensus sequences in the promoter of target genes [192]. The relevance of LRH-1 in the regulation of intestinal GC synthesis has been demonstrated by the fact that mice heterozygous for LRH-1, or with intestinespecific LRH-1 deletion, show strongly impaired intestinal GC synthesis in response to immune cell activation, and are highly sensitized to the induction of experimental colitis [193, 194]. Similarly, we have seen that infection of mice with LCMV (lymphocytic choriomeningitis virus) results in infection of both, small and large intestine, which promotes a strong anti-viral immune response, as visualized by the expansion of cytotoxic $\mathrm{T}$ cells in the intestinal mucosa. This process is accompanied by an increase in local GC synthesis in small and large intestine. More importantly, reduced intestinal GC synthesis, i.e., in mice with intestine-specific LRH-1 deletion, results in significantly increased expansion and activation of virus-specific T cells [189, 195]. Thus, intestinal GC synthesis clearly contributes to the regulation of local immune homeostasis.

Induction of TNF expression is a frequent consequence of viral infections and associated immune responses, as well as intestinal inflammation in general. This is also the case in intestinal LCMV infection and most forms of experimental colitis [184, 195]. TNF induction could thus, not only contribute to the epithelial damage observed during these inflammatory processes, but it can be also an important link between immune cell activation, inflammation and induction of intestinal GC synthesis. Indeed, it was found that while immune cell activation in wild-type mice results in robust induction of intestinal GC synthesis, it is blunted in TNF-deficient or TNFR-deficient mice [185]. This seems to be a direct effect of TNF on the cells of the intestinal crypts, i.e., the source of immune-regulatory GCs, as direct TNF stimulation of isolated intestinal crypts promoted the expression of steroidogenic enzymes [184]. More interestingly, while TNBS-induced colitis promotes both, intestinal TNF expression and GC synthesis, oxazolone-triggered intestinal inflammation induces a Th2-type of inflammation, yet fails to induce TNF and intestinal GC synthesis. Strikingly, when oxazolone-treated mice were injected in parallel with low doses of TNF, not only intestinal GC synthesis was restored, but signs of inflammation and tissue destruction were drastically reduced [184]. Similarly, while DSS-induced colitis is not dependent on TNF, the 
inflammatory response in the absence of TNF is more severe, likely because no intestinal GC synthesis is induced. On the other hand, therapeutic administration of TNF ameliorates DSS colitis, presumably by increasing intestinal levels of immunoregulatory GCs [184]. These findings clearly support the idea that (i) TNF is an important sensor of intestinal inflammation and inducer of intestinal GC synthesis, and (ii) that locally produced intestinal GCs are important regulators of intestinal inflammation. They also support the notion that TNF in the intestine has a Janus-like behavior; a pro-inflammatory, disease-promoting and tissue-destructive activity early in the inflammation phase, and an anti-inflammatory role later on, which contributes to the resolution of inflammation via the induction of intestinal GC synthesis. Of interest, we have previously seen that in colonic biopsies of IBD patients, the expression of LRH-1 and steroidogenic enzymes was significantly reduced compared to control biopsies [194], suggesting that defective intestinal GC synthesis could contribute to the pathogenesis of IBD. As mentioned above, patients with IBD are frequently treated with immunosuppressive drugs, including GCs. Indeed, the first published used of exogenous GCs (cortisone) administration as a therapy against IBD dates back to 1955 [196]. However, although more than half of IBD patients respond to GC treatment, partial and nonresponders also exist, while other patients develop resistance, leading to a more aggressive phenotype of the disease [197, 198]. Noteworthy, long-term exposure to GCs therapy is often accompanied by a range of detrimental side effects with inflammatory origin, such as type-II diabetes or osteoporosis, considerably limiting the use of GC as a prolonged single therapy [199]. Whether or not the development of GC resistance in IBD patients is related to negative feedback responses on the endogenous local GC synthesis in the intestinal mucosa remains to be investigated, but is an interesting hypothesis to be followed up upon. Furthermore, while it will not be feasible to restore intestinal GC synthesis in IBD patients by treatment with TNF, a better understanding of the regulatory processes involved in intestinal GC synthesis may help to develop new pharmaceutical drugs, specifically targeting this local homeostatic mechanism. In this regard, it is interesting to note that various LRH-1-activating chemical compounds have been characterized [200], which could be potentially used to enhance LRH-1-regulated intestinal GC synthesis.

\section{Concluding remarks}

In summary, the enormous variety and complexity of cellular and tissue responses to TNF are most impressively demonstrated in the intestinal mucosa. In no other tissue TNF has such a drastic and direct cell death-promoting activity as in the intestinal epithelium [48]. At the same time, TNF seems to be an important regulator of intestinal GC synthesis, which represents a critical mechanism of intestinal immune homeostasis. A better understanding of this TNF duality in the initiation, as well as the termination of the inflammatory response will be crucial for a better development of strategies that aim to target more specifically diverse TNF activities in IBD and other inflammatory diseases.

Acknowledgements This work was supported by Grants from the German Science Foundation to TB. MED received an Independent Research Grant from the University of Konstanz "Zukunftskolleg".

Author contributions MED and TB designed and discussed the manuscript. MED wrote the text, while TB edited it.

\section{Compliance with ethical standards}

Conflict of interest The authors declare that they have no conflict of interest.

Publisher's note: Springer Nature remains neutral with regard to jurisdictional claims in published maps and institutional affiliations.

\section{References}

1. Kato T, Owen RL. Structure and function of intestinal mucosal epithelium. In: Mucosal Immunology. 1. 3rd edn. Elsevier Academic Press; 2005.

2. van der Flier LG, Clevers H. Stem cells, self-renewal, and differentiation in the intestinal epithelium. Annu Rev Physiol. 2009;71:241-60.

3. Haegebarth A, Clevers H. Wnt signaling, lgr5, and stem cells in the intestine and skin. Am J Pathol. 2009;174:715-21.

4. Cheng H, Merzel J, Leblond CP. Renewal of Paneth cells in the small intestine of the mouse. Am J Anat. 1969;126:507-25.

5. Ireland H, Houghton C, Howard L, et al. Cellular inheritance of a Cre-activated reporter gene to determine Paneth cell longevity in the murine small intestine. Dev Dyn. 2005;233:1332-6.

6. Williams JM, Duckworth CA, Burkitt MD, et al. Epithelial cell shedding and barrier function: a matter of life and death at the small intestinal villus tip. Vet Pathol. 2015;52:445-55.

7. van Es JH, Clevers H. Paneth cells. Curr Biol. 2014;24:R547R8.

8. Delgado ME, Grabinger T, Brunner T. Cell death at the intestinal epithelial front line. FEBS J. 2016;283:2701-19.

9. Gunther C, Neumann H, Neurath MF, et al. Apoptosis, necrosis and necroptosis: cell death regulation in the intestinal epithelium. Gut. 2013;62:1062-71.

10. Mayhew TM, Myklebust R, Whybrow A, et al. Epithelial integrity, cell death and cell loss in mammalian small intestine. Histol Histopathol. 1999;14:257-67.

11. Ng GZ, Sutton P. The MUC1 mucin specifically inhibits activation of the NLRP3 inflammasome. Genes Immun. 2016;17:203-6.

12. Kim YS, Ho SB. Intestinal goblet cells and mucins in health and disease: recent insights and progress. Curr Gastroenterol Rep. 2010;12:319-30.

13. Pasparakis M. Role of NF-kappaB in epithelial biology. Immunol Rev. 2012;246:346-58. 
14. Shires J, Theodoridis E, Hayday AC. Biological insights into TCRgammadelta+and TCRalphabeta+intraepithelial lymphocytes provided by serial analysis of gene expression (SAGE). Immunity. 2001;15:419-34.

15. Brunner T, Arnold D, Wasem C, et al. Regulation of cell death and survival in intestinal intraepithelial lymphocytes. Cell Death Differ. 2001;8:706-14.

16. Hoytema van Konijnenburg DP, Reis BS, Pedicord VA, et al. Intestinal Epithelial and Intraepithelial T Cell Crosstalk Mediates a Dynamic Response to Infection. Cell. 2017;171:783-94 e13.

17. Cheroutre H, Lambolez F, Mucida D. The light and dark sides of intestinal intraepithelial lymphocytes. Nat Rev Immunol. 2011;11:445-56.

18. Kuka M, Iannacone M. Intestinal flossing keeps pathogens at bay. Dev Cell. 2017;43:383-4.

19. Sheridan BS, Lefrancois L. Intraepithelial lymphocytes: to serve and protect. Curr Gastroenterol Rep. 2010;12:513-21.

20. Leppkes M, Roulis M, Neurath MF, et al. Pleiotropic functions of TNF-alpha in the regulation of the intestinal epithelial response to inflammation. Int Immunol. 2014;26:509-15.

21. Peterson LW, Artis D. Intestinal epithelial cells: regulators of barrier function and immune homeostasis. Nat Rev Immunol. 2014;14:141-53.

22. Hussman JP, Beecham AH, Schmidt M, et al. GWAS analysis implicates NF-kappaB-mediated induction of inflammatory T cells in multiple sclerosis. Genes Immun. 2016;17:305-12.

23. Corazza N, Eichenberger S, Eugster HP, et al. Nonlymphocytederived tumor necrosis factor is required for induction of colitis in recombination activating gene (RAG)2(-/-) mice upon transfer of CD4(+)CD45RB(hi) T cells. J Exp Med. 1999;190:1479-92.

24. Neurath MF, Fuss I, Pasparakis M, et al. Predominant pathogenic role of tumor necrosis factor in experimental colitis in mice. Eur J Immunol. 1997;27:1743-50.

25. Sedger LM, McDermott MFTNF. and TNF-receptors: from mediators of cell death and inflammation to therapeutic giants past, present and future. Cytokine Growth Factor Rev. 2014;25:453-72.

26. Wang XB, Ellis JJ, Pennisi DJ, et al. Transcriptome analysis of ankylosing spondylitis patients before and after TNF-alpha inhibitor therapy reveals the pathways affected. Genes Immun. 2017;18:184-90.

27. Roulis M, Armaka M, Manoloukos M, et al. Intestinal epithelial cells as producers but not targets of chronic TNF suffice to cause murine Crohn-like pathology. Proc Natl Acad Sci USA. 2011;108:5396-401.

28. Moss ML, Jin SL, Milla ME, et al. Cloning of a disintegrin metalloproteinase that processes precursor tumour-necrosis factor-alpha. Nature. 1997;385:733-6.

29. Black RA, Rauch CT, Kozlosky CJ, et al. A metalloproteinase disintegrin that releases tumour-necrosis factor-alpha from cells. Nature. 1997;385:729-33.

30. Chan FK, Chun HJ, Zheng L, et al. A domain in TNF receptors that mediates ligand-independent receptor assembly and signaling. Science. 2000;288:2351-4.

31. Palladino MA, Bahjat FR, Theodorakis EA, et al. Anti-TNFalpha therapies: the next generation. Nat Rev Drug Discov. 2003;2:736-46.

32. Hohmann HP, Remy R, Brockhaus M, et al. Two different cell types have different major receptors for human tumor necrosis factor (TNF alpha). J Biol Chem. 1989;264:14927-34.

33. Fiers W. Tumor necrosis factor. Characterization at the molecular, cellular and in vivo level. FEBS Lett. 1991;285:199-212.

34. Aggarwal BB, Eessalu TE, Hass PE. Characterization of receptors for human tumour necrosis factor and their regulation by gamma-interferon. Nature. 1985;318:665-7.
35. Wang F, Graham WV, Wang Y, et al. Interferon-gamma and tumor necrosis factor-alpha synergize to induce intestinal epithelial barrier dysfunction by up-regulating myosin light chain kinase expression. Am J Pathol. 2005;166:409-19.

36. Musch MW, Clarke LL, Mamah D, et al. T cell activation causes diarrhea by increasing intestinal permeability and inhibiting epithelial Na+/K+-ATPase. J Clin Invest. 2002;110:1739-47.

37. Grell M, Douni E, Wajant H, et al. The transmembrane form of tumor necrosis factor is the prime activating ligand of the $80 \mathrm{kDa}$ tumor necrosis factor receptor. Cell. 1995;83:793-802.

38. Billmeier U, Dieterich W, Neurath MF, et al. Molecular mechanism of action of anti-tumor necrosis factor antibodies in inflammatory bowel diseases. World $\mathrm{J}$ Gastroenterol. 2016;22:9300-13.

39. Aversa G, Punnonen J, de Vries JE. The 26-kD transmembrane form of tumor necrosis factor alpha on activated CD4+ T cell clones provides a costimulatory signal for human B cell activation. J Exp Med. 1993;177:1575-85.

40. Eissner G, Kolch W, Scheurich P. Ligands working as receptors: reverse signaling by members of the TNF superfamily enhance the plasticity of the immune system. Cytokine Growth Factor Rev. 2004;15:353-66.

41. Faustman DL, Davis M. TNF receptor 2 and disease: autoimmunity and regenerative medicine. Front Immunol. 2013;4:478.

42. Lavrik I, Golks A, Krammer PH. Death receptor signaling. J Cell Sci. 2005;118(Pt 2):265-7.

43. Bodmer JL, Schneider P, Tschopp J. The molecular architecture of the TNF superfamily. Trends Biochem Sci. 2002;27:19-26.

44. Gonzalvez F, Ashkenazi A. New insights into apoptosis signaling by Apo2L/TRAIL. Oncogene. 2010;29:4752-65.

45. Fiandalo MV, Kyprianou N. Caspase control: protagonists of cancer cell apoptosis. Exp Oncol. 2012;34:165-75.

46. Piguet PF, Vesin C, Donati Y, et al. TNF-induced enterocyte apoptosis and detachment in mice: induction of caspases and prevention by a caspase inhibitor, ZVAD-fmk. Lab Invest. 1999;79:495-500.

47. Piguet PF, Vesin C, Guo J, et al. TNF-induced enterocyte apoptosis in mice is mediated by the TNF receptor 1 and does not require p53. Eur J Immunol. 1998;28:3499-505.

48. Grabinger T, Bode KJ, Demgenski J, et al. Inhibitor of apoptosis protein-1 regulates tumor necrosis factor-mediated destruction of intestinal epithelial cells. Gastroenterology. 2017;152:867-79.

49. Naude PJ, den Boer JA, Luiten PG, et al. Tumor necrosis factor receptor cross-talk. FEBS J. 2011;278:888-98.

50. Micheau O, Tschopp J. Induction of TNF receptor I-mediated apoptosis via two sequential signaling complexes. Cell. 2003;114:181-90.

51. Wu GS, Burns TF, Zhan Y, et al. Molecular cloning and functional analysis of the mouse homologue of the KILLER/DR5 tumor necrosis factor-related apoptosis-inducing ligand (TRAIL) death receptor. Cancer Res. 1999;59:2770-5.

52. Ting AT, Bertrand MJM. More to Life than NF-kappaB in TNFR1 Signaling. Trends Immunol. 2016;37:535-45.

53. Varfolomeev EE, Ashkenazi A. Tumor necrosis factor: an apoptosis JuNKie? Cell. 2004;116:491-7.

54. Harhaj EW, Dixit VM. Regulation of NF-kappaB by deubiquitinases. Immunol Rev. 2012;246:107-24.

55. Vereecke L, Sze M, Mc Guire C, et al. Enterocyte-specific A20 deficiency sensitizes to tumor necrosis factor-induced toxicity and experimental colitis. J Exp Med. 2010;207:1513-23.

56. Zhang J, Stirling B, Temmerman ST, et al. Impaired regulation of NF-kappaB and increased susceptibility to colitis-associated tumorigenesis in CYLD-deficient mice. $\mathrm{J}$ Clin Invest. 2006;116:3042-9. 
57. Karatzas DN, Xanthopoulos K, Kotantaki P, et al. Inactivation of CYLD in intestinal epithelial cells exacerbates colitis-associated colorectal carcinogenesis - a short report. Cell Oncol. 2016;39:287-93.

58. Karin M, Lin A. NF-kappaB at the crossroads of life and death. Nat Immunol. 2002;3:221-7.

59. Falvo JV, Tsytsykova AV, Goldfeld AE. Transcriptional control of the TNF gene. Curr Dir Autoimmun. 2010;11:27-60.

60. Sabio G, Davis RJ. TNF and MAP kinase signalling pathways. Semin Immunol. 2014;26:237-45.

61. Chang L, Karin M. Mammalian MAP kinase signalling cascades. Nature. 2001;410:37-40.

62. Xia Y, Wu Z, Su B, et al. JNKK1 organizes a MAP kinase module through specific and sequential interactions with upstream and downstream components mediated by its aminoterminal extension. Genes Dev. 1998;12:3369-81.

63. Mak TW, Yeh WC. Signaling for survival and apoptosis in the immune system. Arthritis Res. 2002;4(Suppl 3):S243-52.

64. Wada T, Penninger JM. Mitogen-activated protein kinases in apoptosis regulation. Oncogene. 2004;23:2838-49.

65. Lasa M, Mahtani KR, Finch A, et al. Regulation of cyclooxygenase 2 mRNA stability by the mitogen-activated protein kinase p38 signaling cascade. Mol Cell Biol. 2000;20:4265-74.

66. Winzen R, Kracht M, Ritter B, et al. Thep38 MAP kinase pathway signals for cytokine-induced mRNA stabilization via MAP kinase-activated protein kinase 2 and an AU-rich regiontargeted mechanism. EMBO J. 1999;18:4969-80.

67. Wasserman JD, Freeman M. An autoregulatory cascade of EGF receptor signaling patterns the Drosophila egg. Cell. 1998;95:355-64

68. Xia Z, Dickens M, Raingeaud J, et al. Opposing effects of ERK and JNK-p38 MAP kinases on apoptosis. Science. 1995;270:1326-31.

69. De Smaele E, Zazzeroni F, Papa S, et al. Induction of gadd45beta by NF-kappaB downregulates pro-apoptotic JNK signalling. Nature. 2001;414:308-13.

70. Wicovsky A, Muller N, Daryab N, et al. Sustained JNK activation in response to tumor necrosis factor is mediated by caspases in a cell type-specific manner. J Biol Chem. 2007;282:2174-83.

71. Papa S, Zazzeroni F, Pham CG, et al. Linking JNK signaling to NF-kappaB: a key to survival. J Cell Sci. 2004;117(Pt 22): 5197-208.

72. Malinin NL, Boldin MP, Kovalenko AV, et al. MAP3K-related kinase involved in NF-kappaB induction by TNF, CD95 and IL1. Nature. 1997;385:540-4.

73. Zarnegar BJ, Wang Y, Mahoney DJ, et al. Noncanonical NFkappaB activation requires coordinated assembly of a regulatory complex of the adaptors cIAP1, cIAP2, TRAF2 and TRAF3 and the kinase NIK. Nat Immunol. 2008;9:1371-8.

74. Senftleben U, Cao Y, Xiao G, et al. Activation by IKKalpha of a second, evolutionary conserved, NF-kappa B signaling pathway. Science. 2001;293:1495-9.

75. Xiao G, Harhaj EW, Sun SC. NF-kappaB-inducing kinase regulates the processing of NF-kappaB2 p100. Mol Cell. 2001;7:401-9.

76. Xiao G, Fong A, Sun SC. Induction of p100 processing by NFkappaB-inducing kinase involves docking IkappaB kinase alpha (IKKalpha) to p100 and IKKalpha-mediated phosphorylation. J Biol Chem. 2004;279:30099-105.

77. Liao G, Zhang M, Harhaj EW, et al. Regulation of the NFkappaB-inducing kinase by tumor necrosis factor receptorassociated factor 3-induced degradation. J Biol Chem. 2004;279:26243-50.
78. Kim JY, Morgan M, Kim DG, et al. TNFalpha induced noncanonical NF-kappaB activation is attenuated by RIP1 through stabilization of TRAF2. J Cell Sci. 2011;124(Pt 4):647-56.

79. Yin $\mathrm{L}, \mathrm{Wu} \mathrm{L}, \mathrm{Wesche} \mathrm{H}$, et al. Defective lymphotoxin-beta receptor-induced NF-kappaB transcriptional activity in NIKdeficient mice. Science. 2001;291:2162-5.

80. Wang L, Du F, Wang X. TNF-alpha induces two distinct caspase-8 activation pathways. Cell. 2008;133:693-703.

81. Lavrik IN, Mock T, Golks A, et al. CD95 stimulation results in the formation of a novel death effector domain proteincontaining complex. J Biol Chem. 2008;283:26401-8.

82. Sprick MR, Rieser E, Stahl H, et al. Caspase-10 is recruited to and activated at the native TRAIL and CD95 death-inducing signalling complexes in a FADD-dependent manner but can not functionally substitute caspase-8. EMBO J. 2002;21:4520-30.

83. Chun HJ, Zheng L, Ahmad M, et al. Pleiotropic defects in lymphocyte activation caused by caspase- 8 mutations lead to human immunodeficiency. Nature. 2002;419:395-9.

84. Krueger A, Schmitz I, Baumann S, et al. Cellular FLICEinhibitory protein splice variants inhibit different steps of caspase-8 activation at the CD95 death-inducing signaling complex. J Biol Chem. 2001;276:20633-40.

85. Fricker N, Beaudouin J, Richter P, et al. Model-based dissection of CD95 signaling dynamics reveals both a pro- and antiapoptotic role of c-FLIPL. J Cell Biol. 2010;190:377-89.

86. Safa AR. c-FLIP, a master anti-apoptotic regulator. Exp Oncol. 2012;34:176-84.

87. Budd RC, Yeh WC, Tschopp J. cFLIP regulation of lymphocyte activation and development. Nat Rev Immunol. 2006;6:196-204.

88. Kavuri SM, Geserick P, Berg D, et al. Cellular FLICE-inhibitory protein (cFLIP) isoforms block CD95- and TRAIL death receptor-induced gene induction irrespective of processing of caspase-8 or cFLIP in the death-inducing signaling complex. J Biol Chem. 2011;286:16631-46.

89. Hoffmann JC, Pappa A, Krammer PH, et al. A new C-terminal cleavage product of procaspase- $8, \mathrm{p} 30$, defines an alternative pathway of procaspase-8 activation. Mol Cell Biol. 2009;29:4431-40.

90. Lin Y, Devin A, Rodriguez Y, et al. Cleavage of the death domain kinase RIP by caspase- 8 prompts TNF-induced apoptosis. Genes Dev. 1999;13:2514-26.

91. Kataoka T, Tschopp J. N-terminal fragment of c-FLIP(L) processed by caspase 8 specifically interacts with TRAF2 and induces activation of the NF-kappaB signaling pathway. Mol Cell Biol. 2004;24:2627-36.

92. Neumann L, Pforr C, Beaudouin J, et al. Dynamics within the CD95 death-inducing signaling complex decide life and death of cells. Mol Syst Biol. 2010;6:352.

93. Lavrik IN, Krammer PH. Regulation of CD95/Fas signaling at the DISC. Cell Death Differ. 2012;19:36-41.

94. Micheau O, Lens S, Gaide O, et al. NF-kappaB signals induce the expression of c-FLIP. Mol Cell Biol. 2001;21:5299-305.

95. Kataoka T, Budd RC, Holler N, et al. The caspase- 8 inhibitor FLIP promotes activation of NF-kappaB and Erk signaling pathways. Curr Biol. 2000;10:640-8.

96. Chang L, Kamata H, Solinas G, et al. The E3 ubiquitin ligase itch couples JNK activation to TNFalpha-induced cell death by inducing c-FLIP(L) turnover. Cell. 2006;124:601-13.

97. Piao X, Komazawa-Sakon S, Nishina T, et al. c-FLIP maintains tissue homeostasis by preventing apoptosis and programmed necrosis. Sci Signal. 2012;5:ra93.

98. Seidelin JB, Coskun M, Vainer B, et al. ERK controls epithelial cell death receptor signalling and cellular FLICE-like inhibitory protein (c-FLIP) in ulcerative colitis. J Mol Med. 2013;91:839-49. 
99. Vandenabeele P, Declercq W, Van Herreweghe F, et al. The role of the kinases RIP1 and RIP3 in TNF-induced necrosis. Sci Signal. 2010;3:re4.

100. Pasparakis M, Vandenabeele P. Necroptosis and its role in inflammation. Nature. 2015;517:311-20.

101. Sun X, Yin J, Starovasnik MA, et al. Identification of a novel homotypic interaction motif required for the phosphorylation of receptor-interacting protein (RIP) by RIP3. J Biol Chem. 2002;277:9505-11.

102. Galluzzi L, Kepp O, Kroemer G. RIP kinases initiate programmed necrosis. J Mol Cell Biol. 2009;1:8-10.

103. Galluzzi L, Vitale I, Aaronson SA, et al. Molecular mechanisms of cell death: recommendations of the Nomenclature Committee on Cell Death 2018. Cell Death Differ. 2018;25:486-541.

104. Oberst A, Dillon CP, Weinlich R, et al. Catalytic activity of the caspase-8-FLIP(L) complex inhibits RIPK3-dependent necrosis. Nature. 2011;471:363-7.

105. Feng S, Yang Y, Mei Y, et al. Cleavage of RIP3 inactivates its caspase-independent apoptosis pathway by removal of kinase domain. Cell Signal. 2007;19:2056-67.

106. O'Donnell MA, Perez-Jimenez E, Oberst A, et al. Caspase 8 inhibits programmed necrosis by processing CYLD. Nat Cell Biol. 2011;13:1437-42.

107. Wright A, Reiley WW, Chang M, et al. Regulation of early wave of germ cell apoptosis and spermatogenesis by deubiquitinating enzyme CYLD. Dev Cell. 2007;13:705-16.

108. Pierdomenico M, Negroni A, Stronati L, et al. Necroptosis is active in children with inflammatory bowel disease and contributes to heighten intestinal inflammation. Am J Gastroenterol. 2014;109:279-87.

109. Gunther C, Martini E, Wittkopf N, et al. Caspase- 8 regulates TNF-alpha-induced epithelial necroptosis and terminal ileitis. Nature. 2011;477:335-9.

110. Welz PS, Wullaert A, Vlantis K, et al. FADD prevents RIP3mediated epithelial cell necrosis and chronic intestinal inflammation. Nature. 2011;477:330-4.

111. Henry CM, Martin SJ. Caspase- 8 acts in a non-enzymatic role as a scaffold for assembly of a pro-inflammatory "FADDosome" Complex upon TRAIL Stimulation. Mol Cell. 2017;65:715-29 e5.

112. Caprioli F, Stolfi C, Caruso R, et al. Transcriptional and post-translational regulation of Flip, an inhibitor of Fasmediated apoptosis, in human gut inflammation. Gut. 2008;57:1674-80.

113. Zhao Q, Yu X, Zhang $\mathrm{H}$, et al. RIPK3 mediates necroptosis during embryonic development and postnatal inflammation in Fadd-deficient mice. Cell Rep. 2017;19:798-808.

114. Dondelinger Y, Aguileta MA, Goossens V, et al. RIPK3 contributes to TNFR1-mediated RIPK1 kinase-dependent apoptosis in conditions of cIAP1/2 depletion or TAK1 kinase inhibition. Cell Death Differ. 2013;20:1381-92.

115. Zelic M, Roderick JE, O'Donnell JA, et al. RIP kinase 1dependent endothelial necroptosis underlies systemic inflammatory response syndrome. J Clin Invest. 2018;128:2064-75.

116. Newton K, Dugger DL, Maltzman A, et al. RIPK3 deficiency or catalytically inactive RIPK1 provides greater benefit than MLKL deficiency in mouse models of inflammation and tissue injury. Cell Death Differ. 2016;23:1565-76.

117. Takahashi N, Vereecke L, Bertrand MJ, et al. RIPK1 ensures intestinal homeostasis by protecting the epithelium against apoptosis. Nature. 2014;513:95-9.

118. Dannappel M, Vlantis K, Kumari S, et al. RIPK1 maintains epithelial homeostasis by inhibiting apoptosis and necroptosis. Nature. 2014;513:90-4.

119. Lee TH, Shank J, Cusson N, et al. The kinase activity of Rip1 is not required for tumor necrosis factor-alpha-induced IkappaB kinase or p38 MAP kinase activation or for the ubiquitination of Rip1 by Traf2. J Biol Chem. 2004;279:33185-91.

120. Berger SB, Kasparcova V, Hoffman S, et al. Cutting Edge: RIP1 kinase activity is dispensable for normal development but is a key regulator of inflammation in SHARPIN-deficient mice. J Immunol. 2014;192:5476-80.

121. O'Donnell MA, Legarda-Addison D, Skountzos P, et al. Ubiquitination of RIP1 regulates an NF-kappaB-independent celldeath switch in TNF signaling. Curr Biol. 2007;17:418-24.

122. Newton K, Dugger DL, Wickliffe KE, et al. Activity of protein kinase RIPK3 determines whether cells die by necroptosis or apoptosis. Science. 2014;343:1357-60.

123. Wang CY, Mayo MW, Korneluk RG, et al. NF-kappaB antiapoptosis: induction of TRAF1 and TRAF2 and c-IAP1 and cIAP2 to suppress caspase-8 activation. Science. 1998;281:16803.

124. Van Antwerp DJ, Martin SJ, Kafri T, et al. Suppression of TNFalpha-induced apoptosis by NF-kappaB. Science. 1996;274:7879.

125. Li X, Yang Y, Ashwell JD. TNF-RII and c-IAP1 mediate ubiquitination and degradation of TRAF2. Nature. 2002;416:345-7.

126. Giampazolias E, Zunino B, Dhayade S, et al. Mitochondrial permeabilization engages NF-kappaB-dependent anti-tumour activity under caspase deficiency. Nat Cell Biol. 2017;19:1116-29.

127. Vlantis K, Wullaert A, Polykratis A, et al. NEMO Prevents RIP Kinase 1-Mediated Epithelial Cell Death and Chronic Intestinal Inflammation by NF-kappaB-Dependent and -Independent Functions. Immunity. 2016;44:553-67.

128. Greten FR, Eckmann L, Greten TF, et al. IKKbeta links inflammation and tumorigenesis in a mouse model of colitisassociated cancer. Cell. 2004;118:285-96.

129. Nenci A, Becker C, Wullaert A, et al. Epithelial NEMO links innate immunity to chronic intestinal inflammation. Nature. 2007;446:557-61.

130. Kajino-Sakamoto R, Inagaki M, Lippert E, et al. Enterocytederived TAK1 signaling prevents epithelium apoptosis and the development of ileitis and colitis. J Immunol. 2008;181:114352.

131. Vanlangenakker N, Vanden Berghe T, Bogaert P, et al. cIAP1 and TAK1 protect cells from TNF-induced necrosis by preventing RIP1/RIP3-dependent reactive oxygen species production. Cell Death Differ. 2011;18:656-65.

132. Legarda-Addison D, Hase H, O'Donnell MA, et al. NEMO/ IKKgamma regulates an early NF-kappaB-independent celldeath checkpoint during TNF signaling. Cell Death Differ. 2009;16:1279-88.

133. Dondelinger Y, Jouan-Lanhouet S, Divert T, et al. NF-kappaBIndependent Role of IKKalpha/IKKbeta in Preventing RIPK1 Kinase-Dependent Apoptotic and Necroptotic Cell Death during TNF Signaling. Mol Cell. 2015;60:63-76.

134. Ashkenazi A, Dixit VM. Death receptors: signaling and modulation. Science. 1998;281:1305-8.

135. Schneider-Brachert W, Tchikov V, Neumeyer J, et al. Compartmentalization of TNF receptor 1 signaling: internalized TNF receptosomes as death signaling vesicles. Immunity. 2004;21:415-28.

136. Siegmund D, Kums J, Ehrenschwender M, et al. Activation of TNFR2 sensitizes macrophages for TNFR1-mediated necroptosis. Cell Death Dis. 2016;7:e2375.

137. Rauert H, Wicovsky A, Muller N, et al. Membrane tumor necrosis factor (TNF) induces $\mathrm{p} 100$ processing via TNF receptor2 (TNFR2). J Biol Chem. 2010;285:7394-404.

138. Wang K, Han G, Dou Y, et al. Opposite role of tumor necrosis factor receptors in dextran sulfate sodium-induced colitis in mice. PLoS One. 2012;7:e52924. 
139. Nakai M, Sudo K, Yamada Y, et al. The role of the tumor necrosis factor receptor in 2,4,6-trinitrobenzene sulfonic acid (TNBS)-induced colitis in mice. Dig Dis Sci. 2005;50:1669-76.

140. Dayer Schneider J, Seibold I, Saxer-Sekulic N, et al. Lack of TNFR2 expression by CD4(+) T cells exacerbates experimental colitis. Eur J Immunol. 2009;39:1743-53.

141. Su L, Nalle SC, Shen L, et al. TNFR2 activates MLCKdependent tight junction dysregulation to cause apoptosismediated barrier loss and experimental colitis. Gastroenterology. 2013;145:407-15.

142. Wajant H, Pfizenmaier K, Scheurich P. Tumor necrosis factor signaling. Cell Death Differ. 2003;10:45-65.

143. Medvedev AE, Sundan A, Espevik T. Involvement of the tumor necrosis factor receptor p75 in mediating cytotoxicity and gene regulating activities. Eur J Immunol. 1994;24:2842-9.

144. Borghi A, Verstrepen L, Beyaert R. TRAF2 multitasking in TNF receptor-induced signaling to NF-kappaB, MAP kinases and cell death. Biochem Pharmacol. 2016;116:1-10.

145. Li L, Soetandyo N, Wang Q, et al. The zinc finger protein A20 targets TRAF2 to the lysosomes for degradation. Biochim Biophys Acta. 2009;1793:346-53.

146. Erickson SL, de Sauvage FJ, Kikly K, et al. Decreased sensitivity to tumour-necrosis factor but normal T-cell development in TNF receptor-2-deficient mice. Nature. 1994;372:560-3.

147. Peschon JJ, Torrance DS, Stocking KL, et al. TNF receptordeficient mice reveal divergent roles for p55 and p75 in several models of inflammation. J Immunol. 1998;160:943-52.

148. Wajant $\mathrm{H}$. The TWEAK-Fn14 system as a potential drug target. Br J Pharmacol. 2013;170:748-64.

149. Vince JE, Chau D, Callus B, et al. TWEAK-FN14 signaling induces lysosomal degradation of a cIAP1-TRAF2 complex to sensitize tumor cells to TNFalpha. J Cell Biol. 2008;182:171-84.

150. Schneider P, Schwenzer R, Haas E, et al. TWEAK can induce cell death via endogenous TNF and TNF receptor 1. Eur J Immunol. 1999;29:1785-92.

151. Ikner A, Ashkenazi A. TWEAK induces apoptosis through a death-signaling complex comprising receptor-interacting protein 1 (RIP1), Fas-associated death domain (FADD), and caspase-8. J Biol Chem. 2011;286:21546-54.

152. Siegmund D, Ehrenschwender M, Wajant H. TNFR2 unlocks a RIPK1 kinase activity-dependent mode of proinflammatory TNFR1 signaling. Cell Death Dis. 2018;9:921.

153. Kiesslich R, Goetz M, Angus EM, et al. Identification of epithelial gaps in human small and large intestine by confocal endomicroscopy. Gastroenterology. 2007;133:1769-78.

154. McElroy SJ, Prince LS, Weitkamp JH, et al. Tumor necrosis factor receptor 1-dependent depletion of mucus in immature small intestine: a potential role in neonatal necrotizing enterocolitis. Am J Physiol Gastrointest Liver Physiol. 2011;301: G656-66.

155. Zeissig S, Burgel N, Gunzel D, et al. Changes in expression and distribution of claudin 2, 5 and 8 lead to discontinuous tight junctions and barrier dysfunction in active Crohn's disease. Gut. 2007;56:61-72.

156. Park JH, Peyrin-Biroulet L, Eisenhut M, et al. IBD immunopathogenesis: a comprehensive review of inflammatory molecules. Autoimmun Rev. 2017;16:416-26.

157. Roda G, Sartini A, Zambon E, et al. Intestinal epithelial cells in inflammatory bowel diseases. World $\mathrm{J}$ Gastroenterol. 2010;16:4264-71.

158. Shaw KA, Cutler DJ, Okou D, et al. Genetic variants and pathways implicated in a pediatric inflammatory bowel disease cohort. Genes Immun. 2018. https://doi.org/10.1038/s41435-018-0015-2.

159. Wallace KL, Zheng LB, Kanazawa Y, et al. Immunopathology of inflammatory bowel disease. World $\mathrm{J}$ Gastroenterol. 2014;20:6-21.
160. Komatsu M, Kobayashi D, Saito K, et al. Tumor necrosis factoralpha in serum of patients with inflammatory bowel disease as measured by a highly sensitive immuno-PCR. Clin Chem. 2001;47:1297-301.

161. Braegger CP, Nicholls S, Murch SH, et al. Tumour necrosis factor alpha in stool as a marker of intestinal inflammation. Lancet. 1992;339:89-91.

162. Eichele DD, Kharbanda KK. Dextran sodium sulfate colitis murine model: an indispensable tool for advancing our understanding of inflammatory bowel diseases pathogenesis. World $\mathrm{J}$ Gastroenterol. 2017;23:6016-29.

163. Sashio H, Tamura K, Ito R, et al. Polymorphisms of the TNF gene and the TNF receptor superfamily member $1 \mathrm{~B}$ gene are associated with susceptibility to ulcerative colitis and Crohn's disease, respectively. Immunogenetics. 2002;53:1020-7.

164. Pierik M, Vermeire S, Steen KV, et al. Tumour necrosis factoralpha receptor 1 and 2 polymorphisms in inflammatory bowel disease and their association with response to infliximab. Aliment Pharmacol Ther. 2004;20:303-10.

165. Watts L, Karaderi T, Roberts A, et al. The severity of ankylosing spondylitis and responses to anti-tumour necrosis factor biologics are not influenced by the tumour necrosis factor receptor polymorphism incriminated in multiple sclerosis. Genes Immun. 2018. https://doi.org/10.1038/s41435-018-0017-0.

166. Senhaji N, Serrano A, Badre W, et al. Association of inflammatory cytokine gene polymorphisms with inflammatory bowel disease in a Moroccan cohort. Genes Immun. 2016;17:60-5.

167. Holtmann MH, Douni E, Schutz M, et al. Tumor necrosis factorreceptor 2 is up-regulated on lamina propria T cells in Crohn's disease and promotes experimental colitis in vivo. Eur J Immunol. 2002;32:3142-51.

168. Funderburg NT, Stubblefield Park SR, Sung HC, et al. Circulating $\mathrm{CD} 4(+)$ and $\mathrm{CD} 8(+) \mathrm{T}$ cells are activated in inflammatory bowel disease and are associated with plasma markers of inflammation. Immunology. 2013;140:87-97.

169. Plevy SE, Landers CJ, Prehn J, et al. A role for TNF-alpha and mucosal T helper-1 cytokines in the pathogenesis of Crohn's disease. J Immunol. 1997;159:6276-82.

170. Li X, Kimberly RP. Targeting the Fc receptor in autoimmune disease. Expert Opin Ther Targets. 2014;18:335-50.

171. Ha C, Mathur J, Kornbluth A. Anti-TNF levels and anti-drug antibodies, immunosuppressants and clinical outcomes in inflammatory bowel disease. Expert Rev Gastroenterol Hepatol. 2015;9:497-505.

172. Connor V. Anti-TNF therapies: a comprehensive analysis of adverse effects associated with immunosuppression. Rheumatol Int. 2011;31:327-37.

173. Siegel SA, Shealy DJ, Nakada MT, et al. The mouse/human chimeric monoclonal antibody $\mathrm{cA} 2$ neutralizes TNF in vitro and protects transgenic mice from cachexia and TNF lethality in vivo. Cytokine. 1995;7:15-25.

174. Weinblatt ME, Kremer JM, Bankhurst AD, et al. A trial of etanercept, a recombinant tumor necrosis factor receptor:Fc fusion protein, in patients with rheumatoid arthritis receiving methotrexate. N Engl J Med. 1999;340:253-9.

175. Hutas G. Golimumab as the first monthly subcutaneous fully human anti-TNF-alpha antibody in the treatment of inflammatory arthropathies. Immunotherapy. 2010;2:453-60.

176. Sandborn WJ, Feagan BG, Stoinov S, et al. Certolizumab pegol for the treatment of Crohn's disease. N Engl J Med. 2007;357:228-38.

177. Corazza N, Brunner T, Buri C, et al. Transmembrane tumor necrosis factor is a potent inducer of colitis even in the absence of its secreted form. Gastroenterology. 2004;127:816-25.

178. Perrier C, de Hertogh G, Cremer J, et al. Neutralization of membrane TNF, but not soluble TNF, is crucial for the treatment of experimental colitis. Inflamm Bowel Dis. 2013;19:246-53. 
179. Chapman AP. PEGylated antibodies and antibody fragments for improved therapy: a review. Adv Drug Deliv Rev. 2002;54: 531-45.

180. Noti M, Corazza N, Mueller C, et al. TNF suppresses acute intestinal inflammation by inducing local glucocorticoid synthesis. J Exp Med. 2010;207:1057-66.

181. Naito Y, Takagi T, Handa O, et al. Enhanced intestinal inflammation induced by dextran sulfate sodium in tumor necrosis factor-alpha deficient mice. J Gastroenterol Hepatol. 2003;18: $560-9$.

182. Zheng L, Fisher G, Miller RE, et al. Induction of apoptosis in mature $\mathrm{T}$ cells by tumour necrosis factor. Nature. 1995;377:348-51.

183. Muller S, Rihs S, Schneider JM, et al. Soluble TNF-alpha but not transmembrane TNF-alpha sensitizes $\mathrm{T}$ cells for enhanced activation-induced cell death. Eur J Immunol. 2009;39: 3171-80.

184. Zhou T, Edwards CK 3rd, Yang P, et al. Greatly accelerated lymphadenopathy and autoimmune disease in lpr mice lacking tumor necrosis factor receptor I. J Immunol. 1996;156:2661-5.

185. Noti M, Corazza N, Tuffin G, et al. Lipopolysaccharide induces intestinal glucocorticoid synthesis in a TNFalpha-dependent manner. FASEB J. 2010;24:1340-6.

186. Buckingham JC. Glucocorticoids: exemplars of multi-tasking. $\mathrm{Br}$ J Pharmacol. 2006;147(Suppl 1):S258-68.

187. Noti M, Sidler D, Brunner T. Extra-adrenal glucocorticoid synthesis in the intestinal epithelium: more than a drop in the ocean? Semin Immunopathol. 2009;31:237-48.

188. Taves MD, Gomez-Sanchez CE, Soma KK. Extra-adrenal glucocorticoids and mineralocorticoids: evidence for local synthesis, regulation, and function. Am J Physiol Endocrinol Metab. 2011;301:E11-24.

189. Cima I, Corazza N, Dick B, et al. Intestinal epithelial cells synthesize glucocorticoids and regulate $\mathrm{T}$ cell activation. J Exp Med. 2004;200:1635-46.
190. Atanasov AG, Leiser D, Roesselet C, et al. Cell cycle-dependent regulation of extra-adrenal glucocorticoid synthesis in murine intestinal epithelial cells. FASEB J. 2008;22:4117-25.

191. Lee YK, Choi YH, Chua S, et al. Phosphorylation of the hinge domain of the nuclear hormone receptor LRH-1 stimulates transactivation. J Biol Chem. 2006;281:7850-5.

192. Fayard E, Auwerx J, Schoonjans K. LRH-1: an orphan nuclear receptor involved in development, metabolism and steroidogenesis. Trends Cell Biol. 2004;14:250-60.

193. Mueller M, Cima I, Noti M, et al. The nuclear receptor LRH-1 critically regulates extra-adrenal glucocorticoid synthesis in the intestine. J Exp Med. 2006;203:2057-62.

194. Coste A, Dubuquoy L, Barnouin R, et al. LRH-1-mediated glucocorticoid synthesis in enterocytes protects against inflammatory bowel disease. Proc Natl Acad Sci USA. 2007;104:13098-103.

195. Huang J, Jia R, Brunner T. Local synthesis of immunosuppressive glucocorticoids in the intestinal epithelium regulates antiviral immune responses. Cell Immunol. 2018;334:1-10.

196. Truelove SC, Witts LJ. Cortisone in ulcerative colitis; final report on a therapeutic trial. Br Med J. 1955;2:1041-8.

197. Castro-Santos P, Suarez A, Lopez-Rivas L, et al. TNFalpha and IL-10 gene polymorphisms in inflammatory bowel disease. Association of -1082 AA low producer IL-10 genotype with steroid dependency. Am J Gastroenterol. 2006;101:1039-47.

198. Dubois-Camacho K, Ottum PA, Franco-Munoz D, et al. Glucocorticosteroid therapy in inflammatory bowel diseases: From clinical practice to molecular biology. World J Gastroenterol. 2017;23:6628-38.

199. McDonough AK, Curtis JR, Saag KG. The epidemiology of glucocorticoid-associated adverse events. Curr Opin Rheumatol. 2008;20:131-7.

200. Lee JM, Lee YK, Mamrosh JL, et al. A nuclear-receptordependent phosphatidylcholine pathway with antidiabetic effects. Nature. 2011;474:506-10. 